\title{
Risco e Competição Bancária no Brasil*
}

\author{
Luiz Alberto D’Ávila de Araújo ${ }^{\dagger}$, Paulo de Melo Jorge Neto $\ddagger$
}

Sumário: 1. Introdução; 2. Competição Bancária; 3. Sistema Financeiro e Risco; 4. Concentração; 5. Competição e Risco; 6. Caso Brasileiro; 7. Conclusão; A. Amostra de Bancos Comerciais Individuais (CNPJ); B. Teste para a Estatística-H=0 (Monopólio) e Estatística-H=1 (Concorrência); C. Testes para Termos Iguais, Efeitos Fixos e Aleatórios.

Palavras-chave: competição bancária; risco financeiro; regulação bancária.

Códigos JEL: D89; E61; G28.

Diante dos dilemas de regulação bancária está a dicotomia entre liberalização, a qual induz maior competição, e estabilização do sistema financeiro. Neste contexto, este artigo investiga o relacionamento entre o nível de risco e o grau de competição bancária no Brasil, utilizando a estatística-H do modelo de Panzar \& Rosse e o Índice de Basiléia, como medidas de competição e risco, respectivamente. Dada a relevância do debate, mensurou-se uma segunda medida de estrutura de mercado por meio do grau de concentração. Os resultados deste trabalho mostram que os bancos brasileiros operam em concorrência monopolista e que a competição implica numa maior exposição ao risco.

One of the most relevant discussions on bank regulation is the dichotomy between liberalization, with higher competition, and financial stability. To investigate this problem, the article examines competitive conditions and risk taking in Brazilian banks, and investigates their relationship. Competition is measured using Panzar \& Rosse model and risk taking by Basel Brazilian Index. Given the relevance of the discussion, we use the concentration index as a measure of market structure. It is shown that Brazilian banks operate in monopolist competition and that competition increases risk taking.

\footnotetext{
*Este trabalho contém comentários e sugestões feitas por Luiz Ivan de Melo Castelar e Carlos Hamilton Vasconcelos Araújo, aos quais somos muito gratos. Agradecemos ao Banco Central do Brasil pelo fornecimento de dados essenciais ao desenvolvimento do trabalho. Todos os erros e omissões são de responsabilidade dos autores.

${ }^{\dagger}$ As opiniões expressas neste artigo são, exclusivamente, do autor e não refletem, necessariamente, a visão do Banco do Brasil S.A. Pesquisador do Banco do Brasil S.A. Mestre em Economia pelo Curso de Pós-graduação em Economia - CAEN. Endereço: SBS Ed. Sede III - $13^{\circ}$ andar - Diretoria Internacional - Banco do Brasil S.A. E-mail: davila@bb.com. br. Fone: (61) $3310-4464$. Fax: (61) 3310-2444

${ }^{\ddagger}$ Professor do Curso de Pós-graduação em Economia - CAEN. PhD University of Illinois - EUA. Endereço: Av. da Universidade 2700, $2^{\circ}$ andar. Fortaleza CE, 60020-181. E-mail: pjnet o@caen. ufc. br. Fone: (85) 4009-7750. Fax: (85) 4009-7753
} 


\section{INTRODUÇÃO}

O sistema bancário brasileiro enfrentou grandes transformações com o lançamento do Plano Real. Muitos bancos perderam os ganhos propiciados pelas transferências inflacionárias, o que exigiu a adoção de medidas para fortalecer a indústria. Dentre outras medidas adotadas pela autoridade reguladora, estão: a adoção das orientações do Acordo de Basiléia e a redução das restrições à entrada dos bancos estrangeiros.

Com esses dois mecanismos, a autoridade reguladora buscou fortalecer o sistema financeiro por intermédio do enquadramento dos bancos brasileiros ao novo padrão de solvência e liquidez internacional e do aumento de eficiência dos bancos domésticos via entrada de instituições estrangeiras. Entretanto, não está claro qual tenha sido o impacto esperado desses mecanismos sobre o nível de risco, pois embora a introdução de uma exigência mínima de capital (índice de Basiléia) diminua o risco do sistema bancário, pode-se esperar que a abertura aos bancos estrangeiros aumente a competição, induzindo a ações que elevam o risco. Se por um lado o aumento do volume de crédito pode ser um resultado esperado do aumento da competição, também é esperado que o aumento na concessão de crédito aumente o risco de falência dos bancos.

Além disso, alguns aspectos institucionais do Brasil podem ter influenciado a exposição ao risco, tais como, a não vigência de uma lei de falências apropriada, a recente estabilidade da moeda e a grande participação da dívida interna do setor público no produto interno bruto. Essas características podem ter levado os bancos a operarem com um elevado risco de crédito que, associada a uma grande oferta de títulos públicos federais, proporcionou as condições favoráveis para os intermediários financeiros exibirem sua aversão ao risco, investindo em títulos públicos com elevados retornos sem risco e impedindo um maior direcionamento de recursos para operações de crédito. Segundo (Bolt e Tieman, 2004), ao intensificar a competição na concessão de crédito, os bancos tendem a considerar tomadores de pior qualidade, elevando a exposição e o nível de risco.

Neste contexto, este trabalho tem o objetivo de verificar se a competição no mercado bancário brasileiro está associada ao nível de risco assumido. Para investigar os efeitos da competição, o trabalho define a estatística-H do modelo de Panzar \& Rosse. Já como indicador de risco considera-se o Índice de Basiléia. A utilização do Índice de Basiléia envolve a quantificação da exposição aos riscos de crédito, de crédito em swap, cambial e de taxa de juros.

Posteriormente, considerando a relevância do debate envolvendo Allen e Gale, 2000, 2004, Grochulski e Kareken (2004) e Kahn (2004), foi mensurada uma segunda medida para avaliar os efeitos do grau de competição por meio da estrutura de mercado. Essa medida buscou identificar os efeitos da concentração do mercado bancário. Para tanto, escolheu-se o Índice de Herfindahl-Hirschman. Este debate diz respeito ao impacto da concentração da indústria bancária sobre o nível de risco, indicando a possível existência de um trade-off entre risco e competição.

Campello e Moreno (1996) mostraram que as instituições financeiras brasileiras maiores e com mais possibilidade de exercerem atividades distintas parecem usufruir mais das oportunidades de diversificação, levando a noção de menor risco nos maiores intermediários.

O resultado deste trabalho mostra que, quanto maior o grau de competição maior o nível de exposição ao risco. Entretanto, não mostrou significância na relação entre a competitividade (estatística H) e a concessão de crédito. Em outras palavras, um comportamento mais competitivo pode não levar a uma maior concessão de crédito, mas leva a um maior nível de risco. A iniciativa para dinamizar o sistema financeiro com a facilidade à entrada de bancos estrangeiros e incentivos à competição, possui efeitos colaterais sobre a estabilidade do sistema financeiro. Concomitante a uma maior competição e menor concentração bancária, os bancos tendem a assumir mais risco, comprometendo a estabilidade do sistema.

Este trabalho está dividido da seguinte forma: a seção 2 mensura a estatística de Panzar \& Rosse; a seção 3 mostra a relação entre sistema financeiro e risco e a relevância da discussão envolvendo a utilização de uma medida de concentração; a seção 4 quantifica o Índice de Herfindahl; a seção 5 
esclarece o relacionamento entre risco e competição utilizando o modelo de Bolt \& Tieman e define a medida de riscos; a seção 6 mostra os aspectos particulares do sistema financeiro brasileiro, os modelos estimados e os resultados empíricos, e termina com a conclusão.

\section{COMPETIÇÃO BANCÁRIA}

Os modelos da nova organização industrial fornecem o instrumental necessário para quantificar o comportamento competitivo dos mercados. Dentre esses modelos, ${ }^{1}$ destaca-se o de Panzar e Rosse (1987), cujo teste desenvolvido permite a discriminação entre monopólio, concorrência monopolista e competição perfeita.

O teste é derivado de um mercado bancário que determina o produto de equilíbrio e o número de bancos de equilíbrio, através da maximização ao nível do banco e ao nível da indústria, implicando que o banco i maximiza seu lucro quando a receita marginal é igual ao custo marginal:

$$
R_{i}^{\prime}\left(x_{i}, n, z_{i}\right)-C_{i}^{\prime}\left(x_{i}, w_{i}, t_{i}\right)=0
$$

Onde $R_{i}$ é a receita, $C_{i}$ é o custo, $x_{i}$ é o produto do banco i, $\mathrm{n}$ é o número de bancos, $w_{i}$ é um vetor de $\mathrm{m}$ preços de fatores insumos do banco i, $z_{i}$ é um vetor de variáveis exógenas que alteram a função receita do banco, $t_{i}$ é um vetor de variáveis exógenas que alteram a função custo do banco.

Panzar \& Rosse definiram a medida de competição H como a soma das elasticidades da receita na forma reduzida com respeito aos preços dos fatores:

$$
H=\sum_{k=1}^{m} \frac{\partial R_{i}^{*}}{\partial w_{k i}} \cdot \frac{w_{k i}}{R_{i}^{*}}
$$

A diferenciação entre os tipos, utilizando o H, está discriminada na Tabela 1.

Tabela 1 - A Definição do Comportamento Competitivo - Estatística H

\begin{tabular}{cl}
\hline Valores de $\mathrm{H}$ & \multicolumn{1}{c}{ Comportamento Competitivo } \\
\hline$H \leq 0$ & $\begin{array}{l}\text { Equilíbrio de monopólio: cada banco opera independentemente } \\
\text { sob condições de maximização do lucro de monopólio (H é fun- } \\
\\
\text { ção decrescente da elasticidade da demanda) ou do cartel per- } \\
\text { feito. }\end{array}$ \\
$0<H<1$ & $\begin{array}{l}\text { Equilíbrio de livre entrada em competição monopolista (H é fun- } \\
\text { ção crescente da elasticidade demanda). } \\
\text { Competição perfeita: equilíbrio de livre entrada com utilização } \\
\text { da capacidade eficiente total. }\end{array}$ \\
\hline
\end{tabular}

Vários autores já utilizaram o modelo de Panzar \& Rosse, dentre os quais pode-se destacar os trabalhos de De Bandt e Davis (2000) na Alemanha, França, Itália e Estados Unidos; de Belaisch (2003) no Brasil; de Bikker e Groeneveld (2000) em 15 países da EU; de Bikker e Haaf (2002) em 23 países; de Lee e Kim (1995) na Coréia; de Nathan e Neave (1989) no Canadá; de Smith e Tripe (2001) na Nova Zelândia e Torres (2004) na Espanha.

Neste trabalho, a estatística-H de Panzar \& Rosse foi estimada seguindo os trabalhos de Bikker e Haaf (2002) e Belaisch (2003):

$$
\ln R T_{i}=\alpha+\left(\ln w_{i}\right)^{\prime} \beta+\left(\ln Z_{i}\right)^{\prime} \eta+u_{i}
$$

\footnotetext{
${ }^{1}$ Para uma revisão da literatura, ver Bikker e Haaf. (2001).
} 
A variável endógena $R T_{i t}$ considera a receita operacional e a receita não operacional dos bancos comerciais. Os preços unitários de fatores $w_{i t}$, cujos coeficientes compõe o indicador $\mathrm{H}$, correspondem a: DAF que expressa a razão entre as despesas administrativas sobre o número de funcionários, mensurando o custo unitário das despesas administrativas; DOD que expressa a razão entre despesas operacionais menos despesas administrativas sobre o circulante e exigível em longo prazo, mensurando o preço unitário dos recursos captados; e OD que expressa a razão entre as despesas não operacionais sobre o total de ativos deduzidos das contas de compensação, referindo-se ao preço unitário das despesas não operacionais.

As variáveis exógenas $Z_{i t}$ buscam controlar a estimação do somatório das elasticidades da receita por variáveis que refletem: a demanda do mercado (TD); a economia de escala da geração de receita (TAF); o tamanho e dispersão espacial (AGN); e o risco da intermediação (CRD). Para TD é utilizado o valor dos depósitos totais; para TAF é utilizado o valor dos depósitos acrescidos das operações compromissadas e das obrigações por empréstimos e repasses, o que considera uma possível economia de escala no volume das receitas; para AGN é utilizada a razão entre o número de agências do banco sobre o total de agências do sistema, avaliando-se o tamanho do banco em termos espaciais, onde a dispersão espacial do banco estaria relacionada ao aspecto do "too big to fail" dos bancos grandes; para CRD é utilizada a razão das operações de crédito acrescidas de arrendamento mercantil sobre os depósitos acrescidos de obrigações por empréstimos e repasses, onde se pode ter indícios sobre o risco da intermediação financeira.

A estatística-H é utilizada para mensurar o grau de competição no mercado brasileiro numa amostra contendo os bancos comerciais, bancos múltiplos com carteiras comerciais e a caixa econômica fede$\mathrm{ral}^{2}$ que permaneceram no sistema bancário brasileiro no período de junho de 1999 a junho de 2004 . 0 conjunto de informações contém diversos bancos que foram considerados individualmente (ver Apêndice A). Todas as informações estão discriminadas por semestre, por instituição bancária (Cadastro Nacional de Pessoa Jurídica - CNPJ) e por conta do COSIF. Os valores de cada uma das observações estão em R\$ mil e, como prática usual na área bancária, foram atualizados a valores de junho de 2004 pelo IGP-DI.A estimação do somatório da elasticidade da receita fornece os valores da estatística-H para todos os semestres da amostra, e seus parâmetros e resultados estatísticos estão discriminados na Tabela 2.

Como a estatística-H corresponde ao somatório dos coeficientes de lnDAF, lnDOD e lnOD, seus valores estão discriminados na Tabela 3. Para verificar a estrutura do mercado brasileiro, as hipóteses nulas "estatística- $\mathrm{H}=0$ " e "estatística- $\mathrm{H}=1$ " foram verificadas através de um teste de restrição de igualdades, utilizando a abordagem $\mathrm{F}$ e verificando que o mercado bancário brasileiro opera numa estrutura de concorrência monopolista, uma vez que foram rejeitadas as hipóteses nulas de monopólio e concorrência perfeita (ver Apêndice B).

A evolução da estatística-H será utilizada para mensurar a relação entre competição e risco no sistema brasileiro.

\section{SISTEMA FINANCEIRO E RISCO}

Os sistemas financeiros são cruciais para a alocação de recursos, pois canalizam poupança das famílias para as firmas, distribuindo os investimentos entre as firmas e compartilhando os riscos com as famílias e as firmas.

Pode-se distinguir duas estruturas polares de alocação de recursos nos sistemas financeiros, ${ }^{3}$ uma "baseada em mercados financeiros" que é representada pela atividade descentralizada nos mercados de títulos, e outra "baseada em intermediários" representada pelas instituições bancárias. Enquanto a

\footnotetext{
${ }^{2}$ Amostra foi obtida junto ao Banco Central do Brasil - DINFO/DEFIN, Brasília (DF).

${ }^{3}$ Ver Allen e Gale (2000).
} 
Tabela 2 - Junho de 1999 a Junho de 2004 - Estimação da Elasticidade da Receita

\begin{tabular}{|c|c|c|c|c|c|c|c|c|c|}
\hline \multicolumn{10}{|c|}{ Variável Dependente: $\operatorname{lnRT}$} \\
\hline & Constante & $\operatorname{lnDAF}$ & $\operatorname{lnDOD}$ & $\operatorname{lnOD}$ & $\operatorname{lnTD}$ & $\operatorname{lnTAF}$ & $\ln A G N$ & CRD & R2_Ajust \\
\hline \multirow{2}{*}{$\begin{array}{r}\text { 1995_12 coeficiente } \\
\text { estatística-t }\end{array}$} & 0,3081 & 0,1507 & 0,6727 . & $-0,0060$ & 0,0390 & $-0,0975$ & 0,0830 & $-0,0004$ & 0,8053 \\
\hline & 1,0489 & 3,1715 & 78 & 54 & 1,1261 & $-2,7798$ & 3,5822 & $-0,0168$ & \\
\hline \multirow{2}{*}{$\begin{array}{r}1996 \_06 \text { coeficiente } \\
\text { estatística-t }\end{array}$} & 0,0930 & 03 & 73. & 99 & 0,0286 & $-0,0969$ & 59 & $-0,00190$ & 0,7847 \\
\hline & 0,3277 & 6,4526 & 127 & 95 & 1,1865 & & 5,0545 & $-0,0993$ & \\
\hline \multirow{2}{*}{$\begin{array}{r}\text { 1996_12 coeficiente } \\
\text { estatística-t }\end{array}$} & $-0,3197$ & 33 & 107 & 0,0028 & 0,1000 & & 569 & $0,0099 \mathrm{C}$ & 0,688 \\
\hline & $-0,8424$ & 4,2390 & 12,0106 & 0,2568 & 2,3020 & & 2,4854 & 0,2692 & \\
\hline \multirow{2}{*}{$\begin{array}{r}1997 \text { 06 } \begin{array}{c}\text { coeficiente } \\
\text { estatística-t }\end{array} \\
\end{array}$} & $-1,5685$ & 28 & & $-0,0$ & 0,0277 & & & 0,02870 & 0,8569 \\
\hline & $-6,5237$ & & & & 0,9645 & & & 1,2841 & \\
\hline \multirow{2}{*}{$\begin{array}{r}1997 \text { 12 coeficiente } \\
\text { estatística-t }\end{array}$} & $-1,4440$ & & & & 519 & & & -0, & 0,91 \\
\hline & $-7,0131$ & 0,6 & 97 & 45 & 2,5075 & 0 & & $-0,5$ & \\
\hline \multirow{2}{*}{$\begin{array}{r}1998 \text { 06 coeficiente } \\
\text { estatística-t }\end{array}$} & $-0,2$ & 42 & 555 & $-0,0$ & 79 & -0 , & 5 & $-0,01830,6966$ & . \\
\hline & $-0,6596$ & 3 & 66 & 6 & 1, & & 5 & $-0,7$ & \\
\hline \multirow{2}{*}{$\begin{array}{r}\text { 1998_12 coeficiente } \\
\text { estatística-t }\end{array}$} & $-0,1430$ & 0,0698 & 48 & 9 & 06 & 50 & 63 & 147 & , \\
\hline & $-0,4608$ & 46 & 11 & 96 & 16 & -3 & 11 & $-1,1$ & \\
\hline \multirow{2}{*}{$\begin{array}{r}1999 \text { 06 } \begin{array}{c}\text { coeficiente } \\
\text { estatística-t }\end{array} \\
\end{array}$} & $-1,7328$ & 42 & 17 & -0, & 74 & -0 , & 16 & 0,0091 & 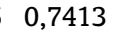 \\
\hline & $-2,6342$ & 0,6 & 40 & 51 & 77 & & 56 & 1,1271 & \\
\hline \multirow{2}{*}{$\begin{array}{r}\text { 1999_12 coeficiente } \\
\text { estatística-t }\end{array}$} & $-0,5088$ & 0,0016 & 0,7434 & 0,0026 & 0,0381 & -0, & 0,0032 & $0,01030,8408$ & 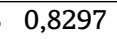 \\
\hline & $-1,3909$ & 0,0475 & 044 & 0,3090 & 1,3946 & -0 , & 0,1561 & 1,9170 & \\
\hline \multirow{2}{*}{$\begin{array}{r}\text { 2000_06 coeficiente } \\
\text { estatística-t }\end{array}$} & $-1,4469$ & 0,0262 & 0,6268 & $-0,0019$ & 0,0665 & -0, & 60 & 0,0103 & . \\
\hline & $-3,7373$ & 31 & 72 & 72 & 2,2747 & -0 , & 95 & 0,0620 & \\
\hline \multirow{2}{*}{$\begin{array}{r}2000 \text { 12 coeficiente } \\
\text { estatística-t }\end{array}$} & $-0,0965$ & 0,0143 & 0,6535 & 0,0083 & 0,0194 & $-0,0402$ & 0,0177 & $-0,00380,8828$ & כבוס, \\
\hline & $-0,3038$ & 0,5429 & 23,9925 & 1,0367 & 0,7173 & 29 & 0,9906 & $-0,2192$ & \\
\hline \multirow{2}{*}{$\begin{array}{r}\text { 2001_06 coeficiente } \\
\text { estatística-t }\end{array}$} & $-1,2781$ & 0,0676 & 0,6013 & $-0,0094$ & 0,0000 & 0,0232 & 0,0142 & $0,0034 \quad 0,8187$ & 0,8043 \\
\hline & $-2,9186$ & 1,8152 & 16,2056 & $-1,1159$ & 0,0003 & 0,9752 & 0,6677 & 0,4332 & \\
\hline \multirow{2}{*}{$\begin{array}{r}\text { 2001_12 coeficiente } \\
\text { estatística-t }\end{array}$} & $-0,7726$ & 0,0207 & 0,7035 & $-0,0039$ & $-0,1472$ & $-0,0086$ & 0,0876 & 0,00720 & 0,0417 \\
\hline & $-3,8172$ & 55 & 721 & 34 & $-3,6036$ & & 1,9834 & 0,5022 & \\
\hline \multirow{2}{*}{$\begin{array}{r}2002 \text { _06 coeficiente } \\
\text { estatística-t }\end{array}$} & $-1,0385$ & 0,0403 & 0,7191 & $-0,0039$ & $-0,0065$ & 0,0366 & 0,0039 & $0,00330,8807$ & 0,8703 \\
\hline & $-2,3771$ & 207 & 354 & 18 & 542 & 1,0397 & 0,1808 & 0,4223 & \\
\hline \multirow{2}{*}{$\begin{array}{r}2002 \text { _12 coeficiente } \\
\text { estatística-t }\end{array}$} & $-3,1233$ & 0,0975 & 0,6441 & 0,0231 & $-0,0607$ & 0,1969 & $-0,0587$ & 0,03340, & 0,8227 \\
\hline & $-5,0$ & 95 & 88 & 1, & -1 & & & 2,8 & \\
\hline \multirow{2}{*}{$\begin{array}{r}\text { 2003_06 coeficiente } \\
\text { estatística-t }\end{array}$} & $-0,7639$ & 0,0218 & 0,6044 & 0,0029 & $-0,0681$ & 0,0714 & 0,0030 & $-0,03980$ & 0,8271 \\
\hline & $-1,2494$ & 0,4704 & 17,2518 & 0,2557 & 61 & 19 & 0,0963 & $-3,5482$ & \\
\hline \multirow{2}{*}{$\begin{array}{r}\text { 2003_12 coeficiente } \\
\text { estatística-t }\end{array}$} & $-2,1693$ & 0,0071 & 0,6374 & $-0,0191$ & $-0,0821$ & 0,1718 & 0,0285 & $-0,01450,5357$ & 0,4935 \\
\hline & $-2,5826$ & 0,0974 & 8,6178 & $-1,0030$ & 303 & 2,8350 & 0,5584 & $-0,8829$ & \\
\hline \multirow{2}{*}{$\begin{array}{r}2004 \text { _66 coeficiente } \\
\text { estatística-t }\end{array}$} & $-1,9255$ & 0,1211 & 0,6731 & 0,0200 & $-0,0190$ & 0,0369 & 0,0565 & $-0,1536 c$ & 0,5491 \\
\hline & $-1,8332$ & 1,7853 & 7,3209 & 2,0493 & $-0,2418$ & 0,4131 & 1,0152 & $-1,8388$ & \\
\hline
\end{tabular}


Tabela 3 - Junho de 1999 a Junho de 2004 - Estatística H

\begin{tabular}{|c|c|c|}
\hline Período & Estatística $\mathrm{H}$ & Nr. Bancos \\
\hline 121995 & 0,8174 & 117 \\
\hline 06_1996 & 0,7897 & 122 \\
\hline 12 1996 & 0,8068 & 113 \\
\hline $06 \quad 1997$ & 0,8813 & 101 \\
\hline 12_1997 & 0,8750 & 101 \\
\hline 061998 & 0,6579 & 102 \\
\hline 12_1998 & 0,6737 & 101 \\
\hline 06_1999 & 0,7201 & 112 \\
\hline 12_1999 & 0,7475 & 108 \\
\hline 06_2000 & 0,6511 & 104 \\
\hline 12_2000 & 0,6761 & 96 \\
\hline 06_2001 & 0,6595 & 96 \\
\hline $12 \quad 2001$ & 0,7203 & 93 \\
\hline 06_2002 & 0,7554 & 88 \\
\hline $12 \_2002$ & 0,7646 & 88 \\
\hline 06_2003 & 0,6290 & 86 \\
\hline 12_2003 & 0,6254 & 80 \\
\hline $06 \quad 2004$ & 0,8142 & 78 \\
\hline
\end{tabular}

primeira possui um maior grau de competição e resulta num mercado pouco concentrado, a segunda tem um sistema bancário menos competitivo e mais concentrado.

O contraste entre esses dois tipos de sistemas financeiros sugere que os intermediários e os mercados desenvolvem mais ou menos a mesma função por diferentes caminhos e diferentes graus de sucesso. A comparação entre esses tipos de sistemas financeiros é complexa, vários tipos de sistemas financeiros são observados com graus de competição e intermediários financeiros diferentes, com cada um possuindo suas vantagens e desvantagens.

Allen e Gale (2000) alegam que não há nenhuma premissa teórica sugerindo que os sistemas baseados em intermediários sejam inferiores aos sistemas baseados em mercados. Emem mercados. Em outras palavras, não se pode afirmar a priori que os sistemas menos competitivos sejam piores que os sistemas mais competitivos.

Grochulski e Kareken (2004) criticaram o modelo utilizado por Allen e Gale (2000), segundo o qual, o risco do portfolio dos bancos aumenta com um incremento da competição bancária, mensurada pela quantidade de bancos no mercado. Grochulski \& Kareken mostraram que a tomada de riscos pelos bancos é independente do número de bancos no sistema.

Allen e Gale (2004) mostraram que a maior competição pode ser benéfica para a alocação de recursos na economia e, conseqüentemente, para o crescimento econômico, mas é ruim para a estabilidade financeira. O relacionamento entre competição e estabilidade é complexo, e por algumas vezes a competição pode aumentar a estabilidade. Assim, indicam que existe um conflito entre competição e risco, concluindo que a concentração pode ser socialmente preferível à competição perfeita e que a inexistência de risco no sistema (estabilidade perfeita) pode não ser socialmente desejável.

Kahn (2004) questionou Allen e Gale (2004), indagando se a competição encoraja a estabilidade financeira e se existe um trade-off entre competição e risco. Kahn (2004) critica os autores por terem empregado diversas interpretações para competição e estabilidade, concluindo que estes não adotam uma posição clara se a competição e o risco são objetivos conflitantes e seus argumentos sinalizam, implicitamente, contra intervenções que busquem reduzir o grau de competição. Kahn (2004) finaliza 
dizendo que para impedir os reguladores de combaterem as crises, reduzindo o nível de competição em tempos de normalidade, faz-se necessário assegurar total liberdade para eles adotarem os procedimentos necessários para enfrentar as crises quando elas ocorrerem.

Assim, percebe-se que o debate entre o grau de competição e o nível de exposição ao risco não é consensual na literatura. Nesse sentido, esta pesquisa busca fornecer uma evidência empírica para o caso brasileiro esclarecendo o comportamento em relação ao risco nos bancos comerciais brasileiros.

Para avaliar o nível de risco entre os bancos brasileiros utiliza-se o Índice de Adequação de Capital ou Índice de Basiléia, ${ }^{4}$ medida de risco definida como a razão do Patrimônio de Referência $(\mathrm{PR})^{5}$ sobre o Patrimônio Líquido Exigido (PLE). ${ }^{6}$ Esse índice define limites mínimos de capital e patrimônio líquido para as instituições financeiras, adequando o mercado financeiro brasileiro aos padrões de solvência e liquidez internacionais (Acordo de Basiléia):

$$
\text { Índice Basiléia }=\frac{P R x 100}{\left(\frac{P L E}{F}\right)}=\frac{P R}{P L E} x F \geq 11 \%
$$

O Patrimônio de Referência (PR) foi definido como o somatório do capital nível I e II, englobando o capital próprio e os instrumentos híbridos (capital e dívida) de captação de recursos.

O Patrimônio Líquido Exigido (PLE) quantifica a exigência de capital para cobertura dos riscos de crédito, de crédito em swap, de câmbio/ouro e de taxas de juros. O PLE foi definido da seguinte forma:

$$
P L E=F . A p r+F^{\prime} \sum_{i=1}^{n 1} R C D_{i}+F^{\prime} \cdot \max \left(\left(\sum_{i=1}^{n 2}\left|A p r c_{i}\right|-0,2 P L A\right) ; 0\right)+\sum_{i=1}^{n 3} E C_{i}
$$

Onde:

\section{Risco de Crédito das Operações ativas - Resolução 2.099}

$F$ fator aplicável às operações ativas ponderadas pelo risco.

Apr total do produto de cada ativo ponderado pelos fatores de risco.

\section{Risco de Crédito de Derivativos (Swap) - Resolução 2.399}

$$
R C D_{i}=V N_{i} \sqrt{R^{2} a_{i}+R^{2} p_{i}-2 r a_{i} p_{i} \cdot R a_{i} \cdot R p_{i}}
$$

$F^{\prime}$ fator aplicável ao risco de crédito em operações swap.

$n 1$ número de operações de swap.

$R C D_{i}$ risco de crédito da i-ésima operação de swap.

$V N_{i}$ valor de referência da operação.

$R a_{i}$ risco do referencial ativo da i-ésima operação.

$R p_{i}$ risco do referencial passivo da i-ésima operação.

$r a_{i} p_{i}$ correlação dos referências ativo e passivo da i-ésima operação.

\footnotetext{
${ }^{4}$ Resolução no. 2.099, de 1994.

${ }^{5}$ Resolução no. 2837, de 2001.

${ }^{6}$ Ver Relatório de Estabilidade Financeira do BACEN, de novembro de 2004
} 
Risco de Mercado de Taxa de Câmbio e Ouro - Resolução 2.606

$$
A p r c=\sum_{i=1}^{n 2}\left|A p r c_{i}\right|
$$

$F^{\prime}$ fator aplicável às operações com ouro e variação cambial.

$n 2$ número de posições líquidas em cada moeda e em ouro.

Aprc operações com ouro e variação cambial, incluído mercados derivativos.

$A \operatorname{prc}_{i}$ valores absolutos das posições líquidas em cada moeda e ouro.

Risco de Mercado de Taxa de Juros (prefixadas) - Resolução 2.692

$$
\begin{aligned}
E C_{\text {jurospré }, t} & =\max \left[\left(\frac{M t}{60} \sum_{i=1}^{60} V a R_{t-i}^{\text {Padrão }}\right) ; V a R_{t-1}^{\text {Padrão }}\right] \\
V a R_{t}^{\text {Padrão }} & =\sqrt{\sum_{i=1}^{n} \sum_{j=1}^{n} V a R_{i, t} \cdot V a R_{j, t} \cdot R O_{i, j}} \\
V a R_{i, t} & =2,33 \cdot \frac{P_{i}}{252} \cdot S i g_{t} \cdot V M T M_{i, t} \cdot \sqrt{D} \\
R O_{i, j} & =R O+(1-R O)^{\left(\frac{\max P i, P j}{\min P i P j}\right)^{k}}
\end{aligned}
$$

Onde:

$E C_{i}$ parcela do valor do PLE para cobertura de risco de mercado em determinada moeda.

$n 3$ número de parcelas do valor do PLE para cobertura em determinada moeda.

$M t$ multiplicador para o dia $t$, divulgado diariamente pelo $\mathrm{BC}$, determinado como função decrescente da volatilidade, compreendido entre 1 e 3 .

$V a R_{t}^{\text {Padrão }}$ valor em risco em reais do conjunto de operações do dia $t$.

$V a R_{i, t}$ valor em risco em reais associado ao vértice $P i$ no dia $t$.

$N$ número de vértices.

$P i$ prazos de 21, 42, 63, 126, 252, 504 e 756 dias úteis (vértices).

$\mathrm{Sig}_{t}$ volatilidade padrão para o dia, divulgado diariamente pelo BC.

$V M T M_{i, t}$ soma algébrica em reais dos valores dos fluxos de caixa marcados a mercado no dia t e alocados no vértice $P i$.

$D=10$ (prazo, em dias úteis, necessário para liquidar a posição).

$R O_{i, j}$ correlação entre os vértices $i$ e $j$.

$R O$ parâmetro divulgado no último dia útil de cada mês ou a qualquer tempo pelo BC.

$K$ fator de decaimento, divulgado no último dia de cada mês ou qualquer tempo pelo BC. 
Para ser considerada como desenquadrada em relação ao PLE, uma instituição deve possuir seu índice abaixo de 11\%. Em outras palavras, a instituição está desenquadrada quando seu patrimônio é insuficiente para cobrir os riscos nas operações ativas, passivas e registradas nas contas de compensação.

Esse índice avalia o nível de risco que cada banco brasileiro está exposto e as ponderações na exigência de capital para risco de crédito (Apr) estão diferenciadas pelo tipo de operação ${ }^{7}$ (títulos federais $=$ $0 \%$, operações de crédito $=100 \%$ etc) e não consideram a qualidade dos tomadores de créditos e a possibilidade de gerenciamento do risco de crédito, que envolve o esforço de investigação (para diferenciar entre bons e maus pagadores), técnicas de mitigação do risco e outros mecanismos e políticas de gestão do risco de crédito. ${ }^{8}$ Esses instrumentos de gestão do risco de crédito passarão a ser considerados no novo padrão regulatório conhecido como Basiléia II. ${ }^{9}$

O Índice de Basiléia permite, ainda, que alterações na composição do patrimônio de referência dos bancos alterem o nível de exposição ao risco, sem alterar a exposição medida no PLE. Por exemplo, a utilização de fontes de captação estáveis e de longo prazo como patrimônio de referência aumenta o Índice de Basiléia, lembrando que o aumento desse índice implica em redução do risco. Observe que esse movimento não, necessariamente, está relacionado com o nível de exposição em risco de crédito, de crédito em swap, de câmbio e de taxas de juros.

\section{CONCENTRAÇÃO}

Para considerar os diferentes argumentos entre Allen e Gale (2000) com Grochulski e Kareken (2004) e de Allen e Gale (2004) com Kahn (2004) em um estudo empírico, necessita-se considerar a estrutura de mercado no qual os bancos estão inseridos. Ao invés de considerar apenas o número de bancos, como em Allen e Gale (2004), pode-se considerar explicitamente o grau de competição entre os bancos e utilizar um indicador de competição, conforme a estatística-H de Panzar e Rosse (1987) desenvolvida na seção 2. Por outro lado, é interessante investigar a estrutura de mercado, utilizando uma medida de concentração. Tal medida representaria o grau de competição no mercado bancário.

As medidas de concentração são úteis para indicar, de forma preliminar, os setores que possuem poder de mercado significante. Entretanto, existem alguns problemas com as medidas de concentração: não fornecem informação sobre a evolução temporal das parcelas de cada firma, não consideram que a parcela de mercado de uma empresa possa ser decorrente de custos reduzidos ou produtos de qualidade superior, pressupõe delimitação de mercado ignorando a disciplina dos substitutos comercializados em outros mercados e não avaliam totalmente a participação de uma firma em outra.

$\mathrm{O}$ argumento clássico da Organização Industrial que define a base da tradicional modelagem do paradigma da Estrutura-Conduta-Desempenho (Structure-Conduct-Performance SCP), prevê que a competição é menos vigorosa quando existem poucas firmas no mercado, assumindo que existe uma relação causal entre a concentração e o grau de poder de mercado. Em outras palavras, maior número de firmas causa precificação competitiva, minimizando o poder de mercado que cada firma exerce.

O Índice de Herfindahl-Hirschman ${ }^{10}$ foi escolhido como medida do grau de concentração, pois sua interpretação teórica considera o equilíbrio de um oligopólio homogêneo em competição Cournotem competição Cournot e mostra uma relação entre esse índice e o grau de lucratividade da indústria.

\footnotetext{
${ }^{7}$ Ver Resolução no. 2.099, de 1994.

${ }^{8}$ Ver Jorion (2001).

${ }^{9}$ International Convergence of Capital Measurement and Capital Standards: A Revised Framework (BIS, 2004) e no Brasil está referenciado no Comunicado do Banco Central do Brasil nr. 12.746, de 2004.

${ }^{10}$ Herfindahl (1950) mediram a concentração industrial norte-americana.
} 
A estrutura para apuração da concentração nesse índice toma a seguinte forma:

$$
H H I=\sum_{i=1}^{n} s_{i}^{2}
$$

Onde $s_{i}$ representa a parcela que cada firma detém sobre o total da indústria. Esse índice considera a parcela de mercado de todas as firmas do mercado e ressalta a importância das grandes firmas. Este artigo quantifica a parcela de ativos totais de cada firma.

O Índice de Herfindahl-Hirschman quantifica o tamanho relativo e a distribuição das firmas do mercado num intervalo que vai de $1 / \mathrm{n}$ até 1 . Quando o índice se aproxima de $1 / \mathrm{n}$ é uma indicação de que a estrutura de mercado consiste de um grande número de firmas de tamanho relativamente igual, ou seja, o mercado analisado está num ambiente de concorrência perfeita. Quando o índice se aproxima de 1, representa um monopólio. Esse índice, mensurado para ativo total, será utilizado como medida do grau de concentração no sistema bancário brasileiro.

A Tabela 4 quantificou o índice de concentração considerando os bancos constantes no Apêndice A e pode-se verificar que o sistema brasileiro apresenta uma concentração não muito preocupante comparada com outros países. ${ }^{11}$ Entretanto, para o Índice de Herfindahl-Hirschman caracterizar competição perfeita, deve se aproximar de $1 / \mathrm{n}$, que no período corresponde a valores que variam entre $0,0058 \mathrm{e}$ 0,0072. Em termos gerais, o índice de Herfindahl-Hirschman encontrado para ativos não apresentou alteração significativa, apresentando relativa estabilidade.

Tabela 4 - Índice Herfindahl-Hirschman - Junho de 1999 a Junho de 2004

\begin{tabular}{ccc}
\hline Período & HHI & Nr. de Bancos \\
\hline $06 \_1999$ & 0,0819 & 173 \\
$12 \_1999$ & 0,0770 & 168 \\
06_2000 & 0,0764 & 166 \\
$12 \_2000$ & 0,0735 & 162 \\
$06 \_2001$ & 0,0632 & 158 \\
$12 \_2001$ & 0,0671 & 153 \\
$06 \_2002$ & 0,0675 & 147 \\
$12 \_2002$ & 0,0716 & 145 \\
$06 \_2003$ & 0,0760 & 139 \\
$12 \_2003$ & 0,0799 & 146 \\
$06 \_2004$ & 0,0727 & 147 \\
\hline
\end{tabular}

Nakane (2003) ressaltou que a partir de 2002, com a saída de bancos estrangeiros, os índices de concentração aumentam, mas não se mostram atípicos. Além disso, indicou que a queda do índice para crédito a partir de 2001 está vinculada, quase totalmente, a transferência de parte da carteira de crédito da Caixa Econômica Federal para a Empresa Gestora de Ativos (Emgea), no âmbito do Programa de Fortalecimento das Instituições Financeiras Federais (PROEF).

\section{COMPETIÇÃO E RISCO}

Para investigar os efeitos da competição na tomada do risco vale ressaltar Bolt e Tieman (2004), onde se modela, explicitamente, como os bancos que competem por empréstimos tendem a incorrer em mais risco. A seguir descreve-se rapidamente tal modelo.

\footnotetext{
$\overline{{ }^{11} \text { Ver Bikker e Haaf (2002) para vários países. }}$
} 
O modelo considera a competição de Bertrand entre dois bancos $(i=1,2)$ que operam por $T$ períodos $(t=1, \ldots, T)$, com produto diferenciado. Os gerentes dos bancos são neutros ao risco e são os acionistas do banco. Os gerentes escolhem sua política ótima de empréstimos estipulando o critério de aceitação de empréstimos, que determina o grau de risco do portfolio de empréstimos do banco, $\alpha_{i}\left(\alpha_{i} \geq 0,1=1,2\right)$, cujos altos valores afetam negativamente a qualidade do portfolio de empréstimos $\left(L_{i}\right)$ induzindo uma elevada taxa de falência. O parâmetro $\alpha_{i}$ indica o grau de risco e o banco i enfrenta a seguinte curva de demanda linear:

$$
L_{i}\left(\alpha_{i}, \alpha_{j}\right)=L+l_{1} \alpha_{i}-l_{2} \quad \alpha_{j} l_{1}>l_{2}>0, \quad i, j=1,2 \quad j \neq i .
$$

Os empréstimos dos dois bancos são substitutos imperfeitos, o parâmetro $l_{2}$ representa o grau de substituição entre os empréstimos dos dois bancos e a elevação desse parâmetro aumenta a competição.

As perdas potenciais nos empréstimos são imperfeitamente diversificadas e tem a mesma taxa de retorno nos empréstimos, a probabilidade de não pagamento (integral ou parcial) do empréstimo varia com $\alpha_{i}$, a taxa de empréstimo é exógena e fixa e os empréstimos são precificados pela exposição ao risco.

O parâmetro $\alpha_{i}$ possui dois efeitos: (a) o aumento de $\alpha_{i}$ afeta a qualidade do empréstimo negativamente, reduzindo o retorno esperado do portfolio $R^{e}\left(\alpha_{i}, \alpha_{j}\right)=E\left[\tilde{R}_{i}\left(\alpha_{i}, \alpha_{j}\right)\right]$ e aumentando sua variância $\frac{d R^{e}\left(\alpha_{i}, \alpha_{j}\right)}{d \alpha_{i}}<0 \frac{d v a r\left(\tilde{R}_{i}\left(\alpha_{i}, \alpha_{j}\right)\right)}{d \alpha_{i}}>0$; (b) o segundo efeito mostra que os bancos enfrentam um problema onde a investigação não é perfeita e os bancos não conhecem a trajetória das rejeições anteriores de empréstimos, logo, um cliente com alto risco que é aceito por um banco com baixo critério de investigação tem alta probabilidade de ter sido rejeitado por todos os outros bancos. Assim, bancos que possuem um baixo poder de investigação detém uma grande parte dos clientes com alto risco e a presença desses bancos melhora o risco no portfolio dos outros bancos, ou seja:

$$
\begin{aligned}
\frac{d R^{e}\left(\alpha_{i}, \alpha_{j}\right)}{d \alpha_{i}} & >0 \\
\frac{d v a r\left(\tilde{R}_{i}\left(\alpha_{i}, \alpha_{j}\right)\right)}{d \alpha_{i}} & <0
\end{aligned}
$$

Existe uma razão de solvência mínima que é uma razão do patrimônio líquido sobre empréstimos, definida por $k$, com $0<k<1$. O banco aumentará seu patrimônio líquido mais do que o necessário para aderir as exigências regulatórias, lembrando que o patrimônio líquido é mais caro do que os depósitos. Assim, temos que $E_{i}=k L_{i}, i=1,2$.

A principal conclusão do modelo de Bolt \& Tieman (2004) é que o aumento da competição implica numa maior tomada de risco pelos bancos. O mecanismo é que a maior competição, ceteris paribus, implica em menor lucro por período, que reduz o custo de falência do banco e torna os bancos comerciais mais propensos a tomar risco, aumentando a concessão de empréstimos.

Um incremento na competição da indústria bancária leva o regulador a elevar a exigência de capital mínima, fixa ou ponderada pelo risco. Esse movimento visa reduzir a probabilidade dos bancos comerciais irem a falência.

\section{CASO BRASILEIRO}

O impacto sofrido pelas instituições financeiras brasileiras após o advento do Plano Real ocasionou a adoção de mecanismos para fortalecer o sistema brasileiro. Um desses mecanismos foi estabelecer uma exigência mínima de capital para o sistema financeiro brasileiro, chamada de Índice de Basiléia. Outro mecanismo foi liberalizar o mercado brasileiro aos bancos estrangeiros. 
Tabela 5 - Evolução Temporal do Tipo de Controle e Número de Bancos

\begin{tabular}{rccccccccc}
\hline & 1995 & 1996 & 1997 & 1998 & 1999 & 2000 & 2001 & 2002 & 2003 \\
\hline PN & 144 & 130 & 119 & 105 & 96 & 93 & 82 & 75 & 78 \\
PF & 5 & 5 & 5 & 5 & 7 & 10 & 9 & 9 & 8 \\
PE & 27 & 27 & 22 & 18 & 12 & 7 & 7 & 7 & 6 \\
PCE & 38 & 40 & 45 & 58 & 67 & 69 & 70 & 65 & 62 \\
PPE & 28 & 29 & 26 & 17 & 12 & 13 & 14 & 11 & 10 \\
\hline TOTAL & 242 & 231 & 217 & 203 & 194 & 192 & 182 & 167 & 164 \\
\hline Elaboração própria com os dados da amostra obtida junto ao Banco Central do Brasil, \\
distinção entre PF e PE foi feita pelo autor. Onde: PN = privado nacional, PF = público federal, \\
PE = público estadual, PCE = privado controle estrangeiro (inclui filiais), PPE = privado \\
participação estrangeira.
\end{tabular}

Cysne e da Costa (1997) mostraram os reflexos do Plano Real sobre o sistema bancário brasileiro, concluindo sobre a possibilidade de crises no sistema financeiro devido à redução de receitas inflacionárias e realçaram a inevitável socialização dos passivos não segurados por intermédio do $\operatorname{Proer}^{12}$ e a certeza de se tratar do instrumento menos custoso para enfrentar a crise bancária.

MacKinnon (1973), Shaw (1973) ${ }^{13}$ mostraram o excesso de demanda por crédito nas economias menos industrializadas e propuseram algumas medidas para desregulamentar os mercados financeiros. Uma delas foi eliminar as restrições à entrada, pois um grande número de entrantes estrangeiros elevaria a eficiência dos bancos domésticos, disciplinando o mercado e introduzindo capital e know how no sistema bancário. O objetivo dessa medida é obter melhores produtos e serviços financeiros, com maior concessão de crédito a menores custos e maior investimento.

Demirgüç-Kunt e Detragiache (1998) reforçaram que a necessidade de liberalização financeira deve ocorrer de forma cautelosa se as instituições que garantem a lei, o cumprimento dos contratos e a regulação, não são muito desenvolvidas, mesmo num ambiente de estabilização macroeconômica. Isso decorre do fato de que a liberalização pode aumentar a fragilidade financeira acima do que seja socialmente desejável, quando a regulação prudencial não é efetiva no controle dos bancos.

Campello e Moreno (1996) buscaram indícios das políticas públicas baseadas na idéia de que intermediários maiores e mais diversificados atenderiam aos objetivos de diminuição de custos e manutenção da segurança do sistema financeiro. Seus resultados constataram que os conglomerados maiores e mais diversificados apresentam menos variação do retorno esperado e menores retornos. Logo, se as instituições maiores se beneficiam com a diminuição do risco de não observarem os retornos que esperam pela utilização de estratégias de diversificação de suas operações, isso lhes custa retornos inferiores aos demais participantes.

O reflexo da liberalização do mercado brasileiro aos bancos estrangeiros fez o número de bancos com controle estrangeiro (PCE) passar de 38 (em 1995) para 70 (em 2001), reduzindo em seguida para 62 (em 2003), conforme Tabela 5. Esse fato, isoladamente, poderia sinalizar um incremento da competição e uma maior fragilidade do sistema bancário. Os bancos públicos federais (PF) passaram de cinco (em 1995) para oito (em 2003), em virtude de alguns bancos estaduais serem federalizados, provisoriamente, até sua privatização.

Como a liberalização indica um possível incremento do grau de competição, é importante avaliar esse efeito. Para tanto, têm-se os trabalhos de Nakane (2002), de Petterini e Jorge-Neto (2003) e de

\footnotetext{
${ }^{12}$ PROER - Programa de Estímulo à Reestruturação e ao Sistema Financeiro Nacional, Medida Provisória nr. 1.179, de 1995.

${ }^{13}$ Ver Fry (1995)
} 
Belaisch (2003).

Nakane (2002) fez uma avaliação não estrutural no período de agosto/1994 a agosto/2000 e implementou um teste empírico de poder de mercado para a indústria bancária brasileira baseado na metodologia de Bresnahan (1982) e Lau (1982). Seus resultados mostraram que a indústria bancária brasileira é altamente competitiva, mas o autor rejeitou a hipótese de competição perfeita.

Petterini e Jorge-Neto (2003) avaliaram os resultados da abertura aos bancos estrangeiros no período de junho/1994 a dezembro/2000 e investigaram o grau de competição existente entre os bancos privados brasileiros, utilizando o modelo de Jaumandreu e Lorences (2002). Seus resultados mostraram que os bancos não atuam em conluio e que a estrutura de mercado mais apropriada para operações de crédito é a concorrência monopolista.

Belaisch (2003) utilizou indicadores de lucratividade e eficiência para comparar o sistema brasileiro com o sistema americano, japonês e da área do Euro, além de utilizar o modelo de Panzar e Rosse para avaliar a competitividade dos bancos brasileiros. A autora concluiu que os bancos no Brasil são lucrativos, mas menos eficientes que os bancos americanos, japoneses e da área do Euro. Concluiu, também, que o risco de crédito tem sido alto e que o sistema não é totalmente competitivo, com os bancos brasileiros comportando-se de forma oligopolista.

Apesar da evidência do sistema brasileiro possuir certo grau de competição no período posterior a abertura, a evolução das operações de crédito, leasing e outros créditos (Figura 1) mostra uma redução. Fato que não encontra relação com o aumento nos depósitos. Esse movimento de redução em operações de crédito aconteceu concomitante a redução da concentração considerando Herfindahl-Hirschman e pode ser explicada, a partir de junho de 2001, pela queda no volume de créditos direcionados decorrentes da cessão de parte da carteira de crédito imobiliário da Caixa Econômica Federal (CEF) para a

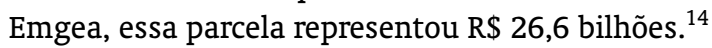

Figura 1 - Evolução dos Ativos, Depósitos e Crédito1 - 1995/12 a 2004/06

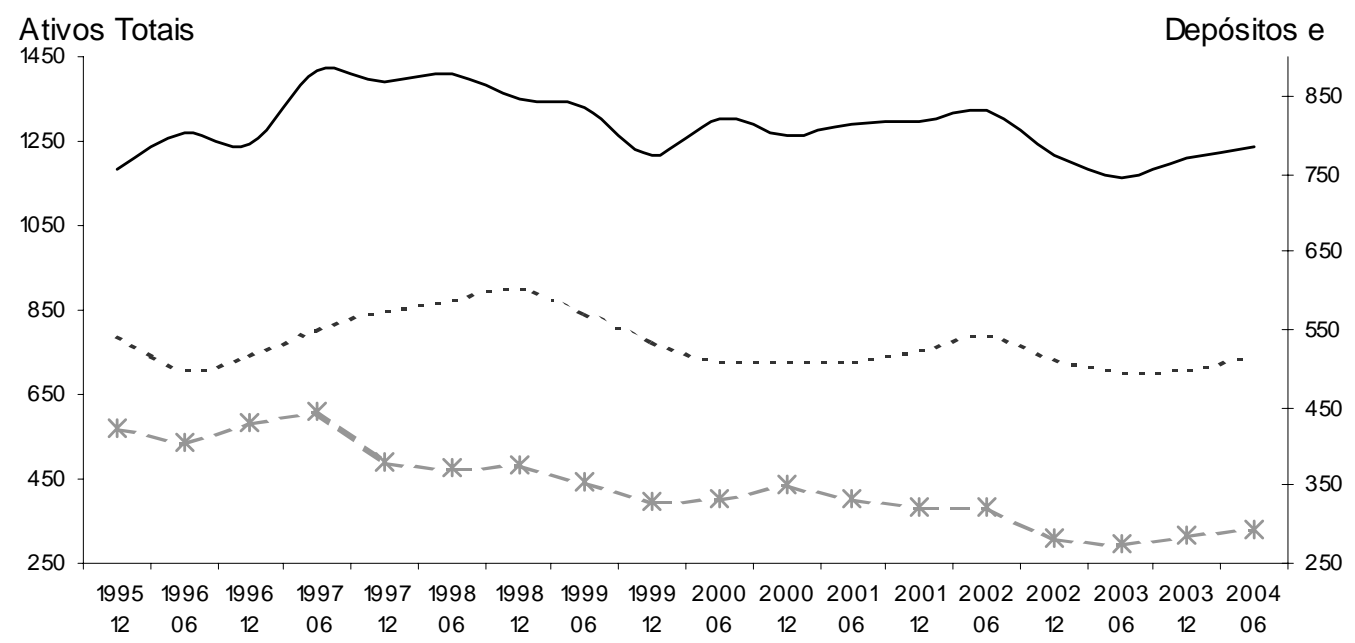

— Ativos Totais $-*--$ Crédito.... .. Depósitos

$\overline{{ }^{14} \text { Ver Relatório de Inflação - Setembro/2001 }}$ Políticas Creditícias, Monetária e Fiscal e Medida Provisória 2.196-3. 
Tabela 6 - Evolução das Operações de Crédito por tipo de Controle

\begin{tabular}{lccccccccc}
\hline & 1995 & 1996 & 1997 & 1998 & 1999 & 2000 & 2001 & 2002 & 2003 \\
\hline $\mathrm{PF}$ & $40 \%$ & $36 \%$ & $43 \%$ & $46 \%$ & $41 \%$ & $35 \%$ & $23 \%$ & $25 \%$ & $28 \%$ \\
$\mathrm{PE}$ & $22 \%$ & $22 \%$ & $9 \%$ & $7 \%$ & $7 \%$ & $4 \%$ & $2 \%$ & $3 \%$ & $5 \%$ \\
$\mathrm{PN}$ & $32 \%$ & $33 \%$ & $35 \%$ & $31 \%$ & $32 \%$ & $35 \%$ & $42 \%$ & $40 \%$ & $41 \%$ \\
$\mathrm{PCE}$ & $6 \%$ & $9 \%$ & $12 \%$ & $15 \%$ & $20 \%$ & $25 \%$ & $32 \%$ & $30 \%$ & $24 \%$ \\
$\begin{array}{l}\text { Cooperativas s de } \\
\text { dito }\end{array}$ & $\mathrm{Cré}-$ & $1 \%$ & $1 \%$ & $1 \%$ & $1 \%$ & $1 \%$ & $2 \%$ & $2 \%$ & $2 \%$ \\
\hline TOTAL & $100 \%$ & $100 \%$ & $100 \%$ & $100 \%$ & $100 \%$ & $100 \%$ & $100 \%$ & $100 \%$ & $100 \%$ \\
\hline $\begin{array}{l}\text { Fonte: Elaboraçao própria com os dados da amostra obtida junto ao Banco Central do Brasil. Obs: discriminação entre PF e } \\
\text { PE feita pelo autor. }\end{array}$
\end{tabular}

Tabela 7 - Evolução dos Ativos por tipo de Controle.

\begin{tabular}{lccccccccc}
\hline & 1995 & 1996 & 1997 & 1998 & 1999 & 2000 & 2001 & 2002 & 2003 \\
\hline PF & $32 \%$ & $30 \%$ & $32 \%$ & $36 \%$ & $34 \%$ & $32 \%$ & $29 \%$ & $30 \%$ & $33 \%$ \\
PE & $20 \%$ & $20 \%$ & $18 \%$ & $10 \%$ & $9 \%$ & $4 \%$ & $3 \%$ & $4 \%$ & $4 \%$ \\
PN & $39 \%$ & $39 \%$ & $37 \%$ & $35 \%$ & $33 \%$ & $35 \%$ & $37 \%$ & $37 \%$ & $41 \%$ \\
PCE & $8 \%$ & $10 \%$ & $13 \%$ & $18 \%$ & $23 \%$ & $27 \%$ & $30 \%$ & $27 \%$ & $21 \%$ \\
$\begin{array}{l}\text { Cooperativas se de } \\
\text { dito }\end{array}$ & $0 \%$ & $0 \%$ & $0 \%$ & $1 \%$ & $1 \%$ & $1 \%$ & $1 \%$ & $1 \%$ & $1 \%$ \\
\hline TOTAL & $100 \%$ & $100 \%$ & $100 \%$ & $100 \%$ & $100 \%$ & $100 \%$ & $100 \%$ & $100 \%$ & $100 \%$ \\
$\begin{array}{l}\text { a Fonte: Elaboração própria com os dados da amostra obtida junto ao Banco Central do Brasil. Obs: discriminação entre PF e } \\
\text { PE feita pelo autor. }\end{array}$
\end{tabular}

As operações de crédito por tipo de controle (Tabela 6) indicam que os bancos públicos estaduais reduziram sua participação de forma expressiva, passando de $22 \%$ (em 1995) para 5\% (em 2003). Enquanto que os bancos com controle estrangeiro tiveram um elevado aumento (de 6\% para 24\%). Esse movimento, possivelmente, reflete as trocas de controle (privatizações) de bancos estaduais ocorridas no período.

O movimento dos bancos federais indicou uma redução, de $40 \%$ (em 1995) para $28 \%$ (em 2003), que é muito significativa e chegou a representar quase metade (23\%, em 2001) da participação em 1995, reflexos das medidas no âmbito do Proef. ${ }^{15}$

A evolução dos ativos por tipo de controle mostra que os bancos públicos federais mantiveram a sua participação em, aproximadamente, $32 \%$ em todo o período, ver Tabela 7 .

Por outro lado, o aprimoramento da regulação prudencial sobre as instituições financeiras brasileiras resultou em algumas ações como a elevação do índice mínimo de adequação de capital de $8 \%$ para 11\%, o aumento do percentual de ponderação do risco sobre os créditos tributários de $20 \%$ para $30 \%$ e a definição pela Resolução 2.682/99 de novos critérios de classificação do risco de crédito e de novos níveis de provisão.

O elevado nível de exposição ao risco dos bancos federais pode ser observado na Tabela 8 e mostra

\footnotetext{
${ }^{15}$ PROEF - Programa de Fortalecimento das Instituições Financeiras Federais, Medida Provisória nr. 2.155, de 2001.
} 
Tabela 8 - Evolução do Índice de Basiléia por Tipo de Controle

\begin{tabular}{rccccccccc}
\hline & 1995 & 1996 & 1997 & 1998 & 1999 & 2000 & 2001 & 2002 & 2003 \\
\hline PF & $9 \%$ & $11 \%$ & $21 \%$ & $11 \%$ & $10 \%$ & $8 \%$ & $13 \%$ & $14 \%$ & $17 \%$ \\
PE & $12 \%$ & $14 \%$ & $38 \%$ & $25 \%$ & $23 \%$ & $24 \%$ & $20 \%$ & $20 \%$ & $25 \%$ \\
PN & $42 \%$ & $30 \%$ & $19 \%$ & $22 \%$ & $19 \%$ & $16 \%$ & $20 \%$ & $18 \%$ & $20 \%$ \\
PCE & $17 \%$ & $20 \%$ & $21 \%$ & $22 \%$ & $18 \%$ & $17 \%$ & $15 \%$ & $17 \%$ & $19 \%$ \\
PPE & $19 \%$ & $19 \%$ & $25 \%$ & $18 \%$ & $18 \%$ & $17 \%$ & $15 \%$ & $16 \%$ & $20 \%$ \\
\hline Mínimo & $8 \%$ & $8 \%$ & $11 \%$ & $11 \%$ & $11 \%$ & $11 \%$ & $11 \%$ & $11 \%$ & $11 \%$ \\
\hline${ }^{a}$ Fonte: Elaboração própria com os dados da amostra obtida junto ao Banco Central do Brasil. \\
Obs: O índice está ponderado pelo ativo de cada banco.
\end{tabular}

que alguns ajustes tornaram-se necessários para o enquadramento desses bancos no Índice de Basiléia. Nesse sentido, o Programa de Fortalecimento das Instituições Financeiras Federais ${ }^{16}$ estabeleceu medidas destinadas ao enquadramento dos bancos federais com elevada exposição ao risco. O plano de adequação patrimonial incluiu, dentre outras medidas: (1) venda de créditos imobiliários para a Emgea; (2) reclassificação de créditos com provisionamentos de recursos; (3) transferência do risco para a União nas operações de crédito com o FGTS, o Fundo Constitucional de Financiamentos do Nordeste (FNE), o Fundo Constitucional do Norte (FNO), o Fundo Constitucional do Centro-oeste e as operações rurais securitizadas; (4) troca por títulos públicos federais de créditos da Lei 8.727/93 (refinanciamento da dívida dos estados), do CVS, do Programa Especial de Saneamento de Ativos (PESA) e dos títulos da dívida externa brasileira (brady bonds); (5) classificação como Patrimônio de Referência Nível II, dos recursos do FNE, FNO e FCO.

Com isso, a liberalização financeira brasileira ocorreu de forma cautelosa, pois após a facilidade para a entrada de bancos estrangeiros, a autoridade monetária aumentou o colchão de proteção (exigência mínima) e promoveu a adequação dos bancos federais, seguindo a posição de Demirgünç-Kunt \& Detragiache e Bolt \& Tieman.

\subsection{A Relação entre Risco e Competição entre os bancos brasileiros}

Conforme Allen e Gale (2004) sugerem, o risco assumido pelos bancos pode ser resultado de um ambiente mais competitivo. Bolt e Tieman (2004), por sua vez, consideram explicitamente, como a competição por empréstimos induz os bancos a assumirem mais risco. Neste sentido, esta seção investiga, empiricamente no Brasil, se existe uma relação entre estrutura de mercado e o nível de risco. Os efeitos da estrutura de mercado serão considerados, inicialmente, como grau de competição do sistema, através do H de Panzar \& Rosse, para em seguida, ser considerado o grau de concentração do mercado.

Como variáveis de controle relevantes na determinação do risco, são consideradas: o tamanho (AGN); o desenquadramento dos bancos públicos (REGPF); o tipo de propriedade do banco (CNT) e o volume de crédito concedido (RCRED). A proxy para risco será o Índice de Basiléia (BASIL) expresso como a razão entre o patrimônio líquido exigido e o patrimônio de referência. Quanto maior for a variável BASIL, menor será o risco do banco. Para REGPF, utiliza-se uma variável dummy multiplicativa que demonstra efeito do desenquadramento dos bancos públicos federais, assume 1 se o banco está desenquadrado e se for banco público federal. Para CNT, utiliza-se uma variável dummy que demonstra o tipo de propriedade do banco $(\mathrm{PF}=$ público federal, $\mathrm{PE}=$ público estadual, $\mathrm{PN}=$ privado nacional, $\mathrm{PCE}=$ privado com controle estrangeiro, PPE = privado com participação estrangeira). Para RCRED, utiliza-se

${ }^{16}$ Medida Provisória no. 2.196, de 2001, autorizou a criação da Empresa Gestora de Ativos (EMGEA). 
a razão entre as operações de crédito acrescido de arrendamento mercantil e outros créditos sobre o total dos ativos deduzidos das contas de compensação, quantifica a disposição do banco em assumir risco de crédito.

Em conseqüência das conclusões de Bolt \& Tieman (2004) tem-se a possibilidade do resíduo da estimação do risco (BASIL) ser correlacionado com o crédito RCRED. Neste sentido, considera-se o crédito como uma variável endógena a ser determinada pelo grau de competição, ou concentração. Como controle tem-se o tamanho do banco (AGN), a estrutura de capital (CAP), o tipo de propriedade do banco (CNT), o enquadramento do banco público (REGPF) e uma variável macroeconômica do volume do endividamento do setor público (DIVPIB). A estrutura de capital do banco (CAP) é expressa pela razão entre o patrimônio líquido sobre o total geral do ativo deduzido das contas de compensação, enquanto DIVPIB é expressa pela razão entre a dívida interna e o produto interno bruto. ${ }^{17}$

Para escolher o método de estimação, considerou-se a possibilidade de que algumas variáveis explicam BASIL e RCRED, simultâneamente. O teste de endogeneidade de Hausman ${ }^{18}$ constatou que existe uma relação entre RCRED e o resíduo da estimação de BASIL, justificando a adoção do método de dois estágios.

O modelo (1) é representado por um sistema com duas equações e duas variáveis endógenas que são o Índice de Basiléia e a concessão de crédito.

$$
\begin{aligned}
\operatorname{RCRED}_{i, t}= & \alpha_{0}+\alpha_{1} A G N_{i, t}+\alpha_{2} C A P_{i, t}+\alpha_{3} H_{t}+\alpha_{4} D I V P I B_{i, t} \\
& +\alpha_{5} \operatorname{REGPF}_{i, t}+\alpha_{6} C N T_{i, t}+u_{i, t} \\
\text { BASIL }_{i, t}= & \beta_{0}+\beta_{1} A G N_{i, t}+\beta_{2} H_{t}+\beta_{3} R C R E D_{i, t}+\beta_{4} R E G P F_{i, t} \\
& +\beta_{5} C N T_{i, t}+v_{i, t}
\end{aligned}
$$

Para resolver o sistema (1) estima-se, ${ }^{19}$ primeiramente, a concessão de crédito RCRED em função da diversificação espacial AGN, da capitalização dos bancos CAP, da razão entre dívida interna do setor público sobre o produto interno bruto DIVPIB, os bancos federais desenquadrados REGPF, da variável central de Bolt \& Tieman que é a competição $\mathrm{H}$ e do tipo de propriedade CNT. O segundo consiste em estimar o nível de risco BASIL, que considera os valores estimados da concessão de crédito RCRED, a diversificação espacial AGN, o banco federal desenquadrado, a competição $\mathrm{H}$ e o tipo de propriedade CNT.

Na estimação da concessão de crédito RCRED espera-se que a competição H, a diversificação espacial AGN, a capitalização do banco CAP e os bancos federais desenquadrados REGPF tenham efeito positivo sobre a concessão de crédito, pois se espera que a maior competição aumente a concessão de crédito seguindo Bolt \& Tieman, a maior quantidade de agências implique em maior concessão de crédito, o maior grau de capitalização aumenta a concessão de crédito devido ao viés dos acionistas em favor do lucro e o banco federal desenquadrado deve ter efeito positivo pela sua exposição ao risco até 2001, respectivamente. Entretanto, a dívida interna do setor público deve ter um efeito negativo, pois se espera que o aumento da dívida canalize recursos que seriam direcionados para operações de crédito.

$\mathrm{Na}$ estimação do risco, espera-se que a competição $\mathrm{H}$, a concessão de crédito RCRED, a dispersão espacial AGN e o banco federal desenquadrado REGPF tenham efeito negativo sobre o Índice de Basiléia, implicando que existe uma relação positiva com o risco, pois quanto maior o Índice de Basiléia menor é o nível de risco dos bancos. Em outras palavras, espera-se que a maior competição reduza o Índice de Basiléia (aumente o risco) seguindo Bolt e Tieman (2004), a concessão de crédito mensurada pela

\footnotetext{
${ }^{17} \mathrm{~A}$ razão da dívida interna sobre o Produto Interno Bruto (PIB) é obtida pelo IPEADATA.

${ }^{18}$ Estimou-se RCRED em função do intercepto e da variável instrumental (RCRED defasado). Em seguida, utilizou-se o resíduo dessa estimação como variável explicativa da estimação de BASIL, cujo coeficiente apresentou estatística t superior a três.

${ }^{19}$ Utilizou-se uma amostra com os sessenta bancos que tiveram CNPJ ativo durante todo o período da análise. Uma lista dos bancos está no Apêndice A.
} 
variável RCRED deve implicar num menor Índice de Basiléia, também, seguindo Bolt e Tieman (2004), o maior tamanho do banco ou sua maior dispersão deve implicar numa maior exposição ao risco (menor BASIL) e o banco federal desenquadrado deve ter um elevado nível de risco (baixo BASIL).

As duas estimações consideraram, ainda, variáveis qualitativas que controlam pelo tipo de propriedade dos bancos da amostra, representada pela variável explicativa CNT que corresponde a PF (público federal), PE (público estadual), PN (privado nacional) e PCE (privado com controle estrangeiro), ficando de fora a variável PPE (privado com participação estrangeira).

Para verificar se o modelo estimado corresponde a efeito comum, fixo ou aleatório, efetuou-se os testes de termos comuns e de Hausman (1978), cujos resultados estão no Apêndice C e concluem pela utilização do modelo de efeitos fixos. Dada a possibilidade de estar-se incorrendo em problemas de heterocedasticidade e autocorrelação, no Apêndice $C$ aparecem, ainda, os testes de heterocedasticidade dentro (within) e entre (between) de Bickel que é uma versão do teste de Breusch-Pagan e os testes de autocorrelação para efeitos fixos de Baltagi (2001), que indicaram a existência de heterocedasticidade e autocorrelação.

Com o objetivo de responder algumas perguntas sobre o relacionamento entre risco e competição, testaremos as seguintes hipóteses: (a) maior competitividade (estatística-H) implica em maior nível de risco, menor BASIL, (b) maior concentração implica em menor nível de risco, maior BASIL, (c) maior competitividade (estatística-H) implica em maior concessão de crédito, RCRED, (d) maior concentração implica em menor concessão de crédito, RCRED e (e) maior concessão de crédito RCRED, implica em maior risco, menor BASIL.

O resultado da estimação de BASIL em função da competição $\mathrm{H}$ pelo método de dois estágios, com modelo de efeitos fixos e GLS corrigindo a heterocedasticidade está descrito na Tabela 9.

Tabela 9 - Risco e Competitividade (Estatística-H) - Dois Estágios

\begin{tabular}{|c|c|c|c|}
\hline \multicolumn{4}{|c|}{$\begin{array}{l}\text { Variável Dependente: RCRED } \\
\text { Método: GLS } \\
\text { Amostra: 1999:1 2004:1 } \\
\text { Observações: } 660\end{array}$} \\
\hline Variável & Coeficiente & Estatística-t & Prob. \\
\hline AGN & 0,7165 & 1,2022 & 0,2298 \\
\hline CAP & $-0,2112$ & $-3,3224$ & 0,0009 \\
\hline $\mathrm{H}$ & 0,0482 & 0,6729 & 0,5013 \\
\hline DIVPIB & 0,0599 & 0,3685 & 0,7126 \\
\hline REGPF & 0,2237 & 5,6766 & 0,0000 \\
\hline $\mathrm{PF}$ & $-0,1202$ & $-2,6654$ & 0,0079 \\
\hline $\mathrm{PE}$ & 0,0091 & 0,1659 & 0,8683 \\
\hline $\mathrm{PN}$ & 0,0965 & 2,2791 & 0,0230 \\
\hline PCE & $-0,0328$ & $-0,7685$ & 0,4425 \\
\hline R-quadrado & 0,9560 & & \\
\hline R2-ajustado & 0,9509 & & \\
\hline
\end{tabular}

\begin{tabular}{|c|c|c|c|}
\hline \multicolumn{4}{|c|}{$\begin{array}{l}\text { Variável Dependente: BRASIL } \\
\text { Método: GLS } \\
\text { Amostra: } 1999: 12004: 1 \\
\text { Observações: } 660\end{array}$} \\
\hline Variável & Coeficiente & Estatística-t & Prob. \\
\hline AGN & 2,9389 & 4,1195 & 0,0000 \\
\hline $\mathrm{H}$ & $-0,1663$ & $-1,8868$ & 0,0597 \\
\hline RCRED & $-2,0646$ & $-4,0250$ & 0,0001 \\
\hline REGPF & 0,3884 & 3,3778 & 0,0008 \\
\hline $\mathrm{PF}$ & 0,0364 & 0,4972 & 0,6192 \\
\hline $\mathrm{PE}$ & 0,0034 & 0,0313 & 0,9751 \\
\hline $\mathrm{PN}$ & 0,1895 & 3,8313 & 0,0001 \\
\hline PCE & 0,0564 & 1,9074 & 0,0570 \\
\hline R-quadrado & 0,8581 & & \\
\hline R2-ajustado & 0,8420 & & \\
\hline
\end{tabular}

Os resultados chegam as mesmas conclusões de Bolt \& Tieman na relação entre competição e concessão de crédito, bem como, competição e risco, mas não mostram significância na relação entre o grau de competição (H) e a concessão de crédito (RCRED). Esse resultado pode estar relacionado com as medidas adotadas no âmbito do Proef.

$O$ resultado mostra que o maior grau de competição $(\mathrm{H})$ implica em maior nível de risco (menor BASIL) e a maior concessão de crédito (RCRED) leva a um maior nível de risco (menor BASIL). Outros pontos mostram que o tamanho do banco é relevante e indicam que quanto maior o banco (AGN) maior é a concessão de crédito (RCRED), respaldando os resultados esperados. 
Na análise do crédito, a capitalização do banco mostrou um efeito inverso ao esperado, uma vez que, quanto mais capitalizado o banco, medido pela razão entre patrimônio líquido e passivo (CAP), menor é a concessão de crédito (RCRED). Os aspectos macroeconômicos (DIVPIB), também, tiveram efeito inverso ao esperado, mas não foram significantes. O banco federal desenquadrado (REGPF) mostrou um impacto diferenciado e positivamente relacionado com a concessão de crédito, conforme esperado.

$\mathrm{Na}$ análise do risco, observa-se que quanto maior o banco (AGN) menor é o nível de risco (maior BASIL), sinalizando que os grandes bancos brasileiros têm um comportamento de aversão ao risco. 0 banco federal desenquadrado (REGPF) é significante na explicação no nível de risco.

Em virtude do debate sobre os trabalhos de Allen e Gale (2004), sobre a relação entre concentração e nível de risco, considerou-se a concentração mensurada pelo índice de Herfindahl-Hirschman para operações de crédito. Assim como no caso da relação entre competição e risco, testou-se heterocedasticidade e autocorrelação (ver Apêndice $C$ ).

O sistema (2) avalia a relação entre concentração e risco, estimando um sistema com duas equações e duas variáveis endógenas, que são o risco (BASIL) e concessão de crédito (RCRED).

$$
\begin{aligned}
\operatorname{RCRED}_{i, t}= & \alpha_{0}+\alpha_{1} A G N_{i, t}+\alpha_{2} C A P_{i, t}+\alpha_{3} H_{H} I_{t}+\alpha_{4} D I V P I B_{i, t} \\
& +\alpha_{5} \operatorname{REGPF}_{i, t}+\alpha_{6} C N T_{i, t}+u_{i, t} \\
B A S I L_{i, t}= & \beta_{0}+\beta_{1} A G N_{i, t}+\beta_{2} H H I_{t}+\beta_{3} R C R E D_{i, t}+\beta_{4} R E G P F_{i, t} \\
& +\beta_{5} C N T_{i, t}+v_{i, t}
\end{aligned}
$$

Para resolver o sistema (2) estima-se, primeiramente, a concessão de crédito RCRED em função da diversificação espacial AGN, da capitalização dos bancos CAP, da razão entre dívida interna do setor público sobre o produto interno bruto DIVPIB, dos bancos federais desenquadrados REGPF, da variável de Allen e Gale (2000) que é a concentração HHI e do tipo de propriedade CNT. O segundo consiste em estimar o nível de risco BASIL, que considera os valores estimados da concessão de crédito RCRED, a diversificação espacial AGN, o banco federal desenquadrado, a concentração HHI, o banco federado desenquadrado e o tipo de propriedade CNT.

Na estimação da concessão de crédito RCRED espera-se que a concentração HHI tenha efeito negativo, implicando que a maior concentração do mercado leve a uma menor concessão de crédito. Na estimação do Índice de Basiléia deve existir um relacionamento positivo entre concentração e Índice de Basiléia, ou seja, a maior concentração de mercado implica em um maior Índice de Basiléia, significando uma menor exposição aos riscos financeiros.

As demais variáveis na estimação da concessão de crédito e do Índice de Basiléia devem ter os mesmos efeitos esperados citados anteriormente.

O resultado da estimação pelo método de dois estágios, com modelo de efeitos fixos e GLS corrigindo a heterocedasticidade está descrito na Tabela 10.

Assim, confirma-se a conclusão de Allen e Gale (2000), mostrando que quanto maior a concentração (HHI) maior é BASIL, ou seja, menor competição implica em menor risco. Da mesma forma, considerando a concentração como proxy do grau de competição, confirma-se a conclusão de Bolt \& Tieman, mostrando que quanto maior a concentração (HHI), menor será a concessão de crédito (RCRED) e menor é o nível de risco (maior BASIL).

O tamanho do banco (AGN) é relevante e indica que bancos maiores concedem mais operações de crédito, e quanto mais capitalizado (CAP) menor é a concessão de crédito. Os aspectos macroeconômicos (DIVPIB) não foram significantes para explicar a concessão de crédito, e o banco federal desenquadrado (REGPF) mostrou um impacto diferenciado e positivamente relacionado com a concessão de crédito.

No acompanhamento do nível de risco, observa-se que quanto maior o banco (AGN) menor é o nível de risco (maior BASIL), sinalizando que os grandes bancos brasileiros têm um comportamento de aversão ao risco. O banco federal desenquadrado (REGPF) é significante na explicação no nível de risco. 
Tabela 10 - Risco e Concentração (HHI) - Dois Estágios

\begin{tabular}{|c|c|c|c|}
\hline \multicolumn{4}{|c|}{$\begin{array}{l}\text { Variável Dependente: RCRED } \\
\text { Método: GLS } \\
\text { Amostra: 1999:1 2004:1 } \\
\text { Observações: } 660\end{array}$} \\
\hline Variável & Coeficiente & Estatística-t & Prob. \\
\hline AGN & 0,8080 & 1,4008 & 0,1618 \\
\hline CAP & $-0,1961$ & $-3,1509$ & 0,0017 \\
\hline HHI & $-2,5475$ & $-3,7412$ & 0,0002 \\
\hline DIVPIB & $-0,0638$ & $-0,3790$ & 0,7048 \\
\hline REGPF & 0,2297 & 5,8232 & 0,0000 \\
\hline $\mathrm{PF}$ & $-0,1183$ & $-2,5598$ & 0,0107 \\
\hline $\mathrm{PE}$ & 0,0252 & 0,4461 & 0,6557 \\
\hline PN & 0,0945 & 2,1606 & 0,0311 \\
\hline PCE & $-0,0363$ & $-0,7934$ & 0,4278 \\
\hline R-quadrado & 0,9544 & & \\
\hline R2-ajustado & 0,9491 & & \\
\hline
\end{tabular}

\begin{tabular}{|c|c|c|c|}
\hline \multicolumn{4}{|c|}{$\begin{array}{l}\text { Variável Dependente: BASIL } \\
\text { Método: GLS } \\
\text { Amostra: 1999:1 2004:1 } \\
\text { Observações: } 660\end{array}$} \\
\hline Variável & Coeficiente & Estatística-t & Prob. \\
\hline AGN & 0,4419 & 1,5732 & 0,1162 \\
\hline HHI & 1,4227 & 1,8939 & 0,0587 \\
\hline RCRED & 1,9888 & 2,5591 & 0,0107 \\
\hline REGPF & $-0,0800$ & $-8,5338$ & 0,0000 \\
\hline PF & 0,2936 & 5,5659 & 0,0000 \\
\hline $\mathrm{PE}$ & $-0,0368$ & $-0,3105$ & 0,7563 \\
\hline PN & 0,0495 & 1,3507 & 0,1773 \\
\hline PCE & 0,1127 & 3,7642 & 0,0002 \\
\hline R-quadrado & 0,8968 & & \\
\hline R2-ajustado & 0,8851 & & \\
\hline
\end{tabular}

\section{CONCLUSÃO}

Este artigo conclui que o maior grau de competição resulta em um maior nível de risco, independente de se considerar como proxy para a estrutura de mercado uma medida do grau do comportamento competitivo ou uma medida de concentração. A estrutura que caracteriza o grau de competição no sistema bancário brasileiro é a concorrência monopolista, uma vez que as hipóteses de concorrência perfeita e monopólio foram rejeitadas nos teste de hipóteses. Tal resultado está em consonância com Belaisch (2003).

Em virtude da discussão envolvendo Allen e Gale, 2000, 2004, Grochulski e Kareken (2004) e Kahn (2004), avaliou-se os efeitos da concentração sobre o risco e concluiu-se que a maior concentração leva a um menor nível de risco (maior é o índice de Basiléia), ou seja, menor competição implica em menor risco. As conclusões teóricas de Bolt e Tieman (2004), também, foram observadas empiricamente e verificou-se que a maior concentração (refletindo menor competição) implica em menor concessão de crédito e, também, em menor nível de risco (maior índice de Basiléia).

Outros resultados sinalizam que quanto maior for o banco maior será a concessão de crédito e que quanto mais capitalizado em relação aos ativos for o banco menor é a concessão de crédito. $O$ banco federal desenquadrado (REGPF) mostrou um impacto diferenciado e positivamente relacionado com a concessão de crédito.

Os resultados deste trabalho indicam que os mecanismos utilizados pelas autoridades brasileiras para estabilizar o sistema financeiro, como a facilidade à entrada de bancos estrangeiros e incentivos à competição, possuem efeitos colaterais sobre a estabilidade do sistema financeiro. Concomitante a uma maior competição e menor concentração bancária, os bancos tendem a assumir mais risco, podendo comprometer a estabilidade do sistema. Neste ambiente torna-se importante que o nível de risco seja administrado por intermédio do cumprimento dos padrões de Basiléia, que devem ser definidos de forma eficiente.

Para finalizar, destaca-se a importância de pesquisar a eficiência dos bancos no gerenciamento de risco, principalmente no risco de crédito, para avaliar os efeitos do novo Acordo de Basiléia a ser implantado no Brasil, chamado de Basiléia II. Nesse acordo, as instituições de maior porte, com atuação internacional e participação significativa no sistema financeiro brasileiro poderão utilizar uma abordagem avançada com base em sistema próprio de classificação de risco (Internal Risk Based Approache - IRB), substituindo a abordagem padrão simplificada. Caso os grandes bancos, incluindo os bancos 
federais, sejam eficientes no gerenciamento do risco de crédito, será possível uma redução no capital regulatório sem uma contrapartida na exposição ao risco, o que pode levar a um aumento do grau de competição entre os bancos, reduzindo os custos das operações de empréstimos e sem elevação da exposição do sistema bancário brasileiro.

\section{Referências Bibliográficas}

Allen, F. \& Gale, D. (2000). Comparing Financial Systems. The MIT Press, Cambridge, MA.

Allen, F. \& Gale, D. (2004). Competition and financial stability. Journal of Money, Credit and Banking, 36(3):453-80. available at http://ideas.repec.org/a/mcb/jmoncb/v36y2004i3p453-80. html.

Baltagi, B. H. (2001). Econometric Analysis of Panel Data. John Wiley \& Sons LTD, New York.

Belaisch, A. (2003). Do brazilian banks compete? Working Paper WP/03/113, IMF.

Bikker, J. \& Groeneveld, J. M. (2000). Competition and concentration in the eu banking industry. Kredit und Kapital, (33):62-98.

Bikker, J. \& Haaf., K. (2001). Measures of competition and concentration: A review of the literature. Research Series Supervision 27, Netherlands Central Bank.

Bikker, J. \& Haaf, K. (2002). Competition, concentration and their relationship: An empirical analysis of the banking industry. Journal of Banking \& Finance, (26):2191-2214.

Bolt, W. \& Tieman, A. F. (2004). Banking competition, risk and regulation. Scandinavian Journal of Economics, 106(4):783-804. available at http://ideas.repec.org/a/bla/scandj/ v106y2004i4p783-804.html.

Bresnahan, T. F. (1982). The oligopoly solution concept is identified. Economics Letters, 10(1-2):87-92. available at http://ideas.repec.org/a/eee/ecolet/v10y1982i1-2p87-92.html.

Campello, M. \& Moreno, R. (1996). Regulamentação, conglomeração, retorno e risco na indústria bancária brasileira: uma perspectiva de longo prazo. Revista Brasileira de Economia, 50(2). available at http://ideas.repec.org/a/fgv/epgrbe/2995.html.

Cysne, R. P. \& da Costa, S. G. S. (1997). Reflexos do plano real sobre o sistema bancário brasileiro. Revista Brasileira de Economia, 51(3). available at http://ideas . repec.org/a/fgv/epgrbe/2988.html.

De Bandt, O. \& Davis, E. P. (2000). Competition, contestability and market structure in european banking sectors on the eve of emu. Journal of Banking \& Finance, 24(6):1045-1066. available at http:// ideas.repec.org/a/eee/jbfina/v24y2000i6p1045-1066.html.

Demirgüç-Kunt, A. \& Detragiache, E. (1998). Financial liberalization and financial fragility. Policy Research Working Paper 1917, Washington DC: World Bank.

Fry, M. (1995). Money, Interest, and Banking in Economic Development. Jonhs Hopkins University Press, Baltimore MD, 2nd edition.

Grochulski, B. \& Kareken, J. (2004). Allen and gale on risk-taking and competition in banking. Finance Research Letters, 1(4):236-240. available at http://ideas.repec.org/a/eee/finlet/ v1y2004i4p236-240.html. 
Hausman, J. A. (1978). Specification tests in econometrics. Econometrica, 46(6):1251-71. available at http://ideas.repec.org/a/ecm/emetrp/v46y1978i6p1251-71.html.

Herfindahl, O. C. (1950). Concentration in the steel industry. Technical report, Columbia University.

Jaumandreu, J. \& Lorences, J. (2002). Modelling price competition across many markets (an application to the spanish loans market). European Economic Review, 46(1):93-115. available at http://ideas . repec. org/a/eee/eecrev/v46y2002i1p93-115.html.

Jorion, P. . (2001). Value at Risk: The New Benchmark for Managing Financial Risk. McGraw-Hill Companies, Inc.

Kahn, C. M. (2004). Comment on "competition and financial stability"by franklin allen and douglas gale. Journal of Money, Credit and Banking, 36(3):481-86. available at http ://ideas.repec.org/a/mcb/ jmoncb/v36y2004i3p481-86.html.

Lau, L. J. (1982). On identifying the degree of competitiveness from industry price and output data. Economics Letters, 10(1-2):93-99. available at http://ideas.repec.org/a/eee/ecolet/ v10y1982i1-2p93-99.html.

Lee, Y. S. \& Kim, S. G. (1995). The effect of entrant on the bank competitiveness in korean banking industry: Using rosse-panzar test. Review of Economics, 43:165-182.

MacKinnon, R. (1973). Money and Capital in Economic Development. Brookings Institution, US.

Nakane, M. I. (2002). A test of competition in brazilian banking. Estudos Econômicos, 32(2):203-224.

Nakane, M. I. (2003). Economia bancária e crédito: Vi concorrência e spread bancário: uma revisão da evidência para o brasil. Technical report, Banco Central do Brasil.

Nathan, A. \& Neave, E. (1989). Competition and contestability in canada's financial system: Empirical results. Canadian Journal of Economics, 22:576-594.

Panzar, J. C. \& Rosse, J. N. (1987). Testing for "monopoly"equilibrium. Journal of Industrial Economics, 35(4):443-56. available at http://ideas.repec.org/a/bla/jindec/v35y 1987i4p443-56. html.

Petterini, F. \& Jorge-Neto (2003). Análise da competição dos bancos privados nacionais nas operações de crédito do sistema financeiro nacional. Technical report, Universidade Federal do Ceará/CAEN.

Shaw, E. (1973). Financial Deepening in Economic Development. Oxford University Press New York, New York.

Smith, R. \& Tripe, D. (2001). Competition and contestability in new zealand's banking system. 14th Australian Finance and Banking Conference.

Torres, A. G. (2004). El grado de competencia en el sistema bancario español. VII Encuentro de Economia Aplicada.

\section{A. AMOSTRA DE BANCOS COMERCIAIS INDIVIDUAIS (CNPJ)}


Tabela 11 - Relação dos Bancos com Carteiras Comerciais - Apuração do $H$ e $H H I$

\begin{tabular}{|c|c|c|c|c|c|}
\hline CNPJ & NOME_CNPJ & CNPJ & NOME_CNPJ & CNPJ & NOME_CNPJ \\
\hline$\overline{0}$ & BANCO DO BRASIL & 28.195 .667 & BANCO ABC BRASIL & 58.257 .619 & BANCO SANTOS \\
\hline 208 & BRB - BANCO DE BRASILIA & 29.030 .467 & DRESDNER BANK BRASIL & 58.497 .702 & BANCO INTERCAP \\
\hline 86.413 & BANCO BNL DO BRASIL & 29.916 .293 & BANCO CINDAM & 58.616 .418 & BANCO FIBRA \\
\hline 183.938 & BANCO GERDAU & 30.131 .502 & BANCO UBS & 59.109 .165 & BANCO VOLKSWAGEN \\
\hline 253.448 & BANCO POTTENCIAL & 30.306 .294 & BANCO PACTUAL & 59.118 .133 & BANCO LUSO BRASILEIRO \\
\hline 360.305 & CAIXA ECONOMICA FEDERAL & 30.723 .886 & BANCO MODAL & 59.285 .411 & BANCO PANAMERICANO \\
\hline 517.645 & BANCO RIBEIRAO PRETO & 31.136 .708 & BFI BANCO & 59.438 .325 & AMERICAN EXPRESS BANK \\
\hline 558.456 & BANCO BGN & 31.198 .187 & BANCO DIMENSAO & 59.531 .103 & BANCO INTERPART \\
\hline 675.688 & BANCO EQUATORIAL & 31.265 .903 & BANCO ICATU & 59.588 .111 & BANCO VOTORANTIM \\
\hline 795.423 & BANCO EMBLEMA S/A & 31.516 .198 & BANCO ITAÚ - BBA & 59.601 .047 & BANCO AGF \\
\hline 1.023 .570 & BANCO RABOBANK & 31.597 .552 & BANCO CLASSICO & 60.044 .112 & DRESDNER BANK \\
\hline 1.181 .521 & BANCO BANSICREDI & 31.880 .826 & BANCO GUANABARA & 60.394 .079 & BANKBOSTON BANCO MULTIPLO \\
\hline 1.522 .368 & BANCO BNP PARIBAS BRASIL & 31.895 .683 & BCO INDUSTRIAL DO BRASIL & 60.498 .557 & BANCO DE TOKYO-MITSUBISHI \\
\hline 1.540 .541 & BANCO BEG & 32.062 .580 & \multicolumn{2}{|c|}{ CREDIT SUISSE FIRST BOSTON60.518.222 } & BCO SUMITOMO MITSUI BRASILEIRO \\
\hline 1.701 .201 & HSBC BANK BRASIL & 32.067 .787 & BANCO EMPRESARIAL & 60.700 .556 & BANCO SANTANDER NOROESTE \\
\hline 2.318 .507 & BANCO KEB DO BRASIL & 32.219 .669 & BANCO FITAL & 60.701 .190 & BANCO ITAÚ \\
\hline 2.801 .938 & BANCO MORGAN STANLEY & 32.254 .138 & BANCO BVA & 60.746 .948 & BANCO BRADESCO \\
\hline 2.831 .756 & BANCO DAIMLERCHRYSLER & 32.504 .094 & BANCO MORADA & 60.850 .229 & BANCO PECUNIA \\
\hline 2.977 .348 & BANCO TOYOTA DO BRASIL & 33.042 .953 & CITIBANK NA & 60.889 .128 & BANCO SOFISA \\
\hline 2.992 .446 & BANCO CNH CAPITAL & 33.066 .408 & BANCO ABN AMRO REAL & 60.892 .304 & BANCO BMD \\
\hline 3.012 .230 & BANCO1NET & 33.098 .518 & BANCO FININVEST & 60.898 .723 & BANCO BCN \\
\hline 3.017 .677 & BANCO JSAFRA & 33.124 .959 & BANCO RURAL & 60.942 .638 & BANCO SUDAMERIS BRASIL \\
\hline 3.323 .840 & BANCO ALFA & 33.132 .044 & BANCO CEDULA & 61.024 .352 & BANCO INDUSVAL \\
\hline 3.468 .907 & BANCO BEMAT & 33.140 .666 & BANKBOSTON, NA & 61.065 .421 & BANCO MERCANTIL DE SPO \\
\hline 3.502 .961 & BANCO PSA FINANCE BRASIL & 33.172 .537 & BANCO JPMORGAN & 61.071 .387 & UNICARD BANCO MÚLTIPLO \\
\hline 3.609 .817 & BANCO CARGILL & 33.349 .358 & BANCO CACIQUE & 61.083 .697 & BANCO MARTINELLI \\
\hline 3.634 .220 & BANCO HONDA & 33.436 .486 & BANCO WACHOVIA & 61.146 .577 & BANCO BARCLAYS \\
\hline 4.064 .077 & BANCO DO ESTADO DO ACRE & 33.461 .468 & BANCO CREDIBANCO & 61.182 .408 & BANCO INVESTCRED UNIBANCO \\
\hline 4.095 .983 & BANCO ABB & 33.479 .023 & BANCO CITIBANK & 61.186 .680 & BANCO BMG \\
\hline 4.184 .779 & BANCO IBI - IBIBANCO & 33.485 .541 & BANCO BOAVISTA & 61.190 .658 & BANCO FIAT \\
\hline 4.562 .120 & BANCO BEA & 33.517 .640 & BANCO SANTANDER & 61.199 .881 & BANCO DIBENS \\
\hline 4.797 .262 & BANCO ESTADO RONDONIA & 33.588 .252 & BANCO INDUSCRED & 61.348 .538 & BANCO FICSA \\
\hline 4.902 .979 & BANCO BASA & 33.603 .457 & BANCO REDE & 61.377 .677 & BANCO CIDADE \\
\hline 4.913 .711 & BANCO BANPARA & 33.644 .196 & BANCO FATOR & 61.411 .633 & BANCO BANESPA \\
\hline 6.271 .464 & BANCO BEM & 33.700 .394 & UNIBANCO & 61.472 .676 & BANCO SANTANDER BRASIL \\
\hline 6.702 .112 & BANCO PONTUAL & 33.760 .497 & CHASE FLEMING & 61.533 .584 & BANCO SOCIETE GENERALE \\
\hline 6.833 .131 & BANCO BEP & 33.794 .033 & BANCO FONTE CINDAM & 61.535 .100 & BANCO ZOGBI \\
\hline 7.196 .934 & BANCO BEC & 33.822 .149 & BANCO VEGA & 61.602 .801 & BANCO ITAMARATI \\
\hline 7.207 .996 & BANCO BMC & 33.852 .567 & BANCO HSBC & 61.790 .390 & BANCO PATENTE \\
\hline 7.216 .674 & BANCO BANFORT & 33.857 .830 & BANCO OPPORTUNITY & 61.820 .817 & BANCO PAULISTA \\
\hline 7.237 .373 & BCO DO NORDESTE DO BRASIL & 33.861 .840 & BANCO APLICAP & 62.027 .453 & BANCO DESTAK \\
\hline 7.450 .604 & BCO INDUSTRIAL E COMERCIA & L33.861.907 & BANCO INTERUNION & 62.073 .200 & BANCO MERRILL LYNCH \\
\hline 8.249 .716 & BANCO HNF & 33.870 .163 & BANCO ALVORADA & 62.136 .254 & BANCO CRUZEIRO DO SUL \\
\hline 9.093 .352 & BANCO PARAIBAN & 33.876 .475 & BANCO PROSPER & 62.144 .175 & BANCO PINE \\
\hline 10.781 .53 & 2BANCO BANORTE & 33.877 .150 & BANCO STERLING & 62.153 .721 & BANCO PORTO SEGURO \\
\hline 10.824 .99 & 3BANCO MERCANTIL & 33.884 .941 & BANCO BANIF PRIMUS & 62.232 .889 & BANCO DAYCOVAL \\
\hline 10.866 .78 & 8BANCO BANDEPE & 33.885 .724 & BANCO BANERJ & 62.331 .228 & DEUTSCHE BANK $\mathrm{S}^{\mathrm{a}}$ \\
\hline 10.995 .58 & 7BANCO SIMPLES & 33.922 .188 & BANK OF AMERICA & 62.421 .979 & BANCO GE CAPITAL \\
\hline 12.275 .74 & 9BANCO ESTADO ALAGOAS & 33.922 .964 & BANCO GULFINVEST & 65.448 .037 & BANCO UNITED \\
\hline 13.005 .83 & OBANCO IOCHPE & 33.923 .111 & BANCO BRASCAN & 68.900 .810 & BANCO RENDIMENTO \\
\hline 13.009 .71 & 7BANCO BANESE & 33.923 .798 & BANCO MAXIMA & 69.057 .453 & BANCO INTERIOR DE SAO PAULO \\
\hline 13.636 .03 & OBANCO EUROBANCO & 34.943 .654 & BANCO DO EST. AMAPA & 69.141 .539 & BANCO CREDIBEL \\
\hline 14.388 .33 & 4PARANA BANCO & 39.114 .764 & BANCO PEBB & 71.027 .866 & BANCO BONSUCESSO \\
\hline 15.114 .36 & 6BANCO BBM S/A & 40.429 .946 & BANCO PORTO REAL & 74.828 .799 & BANCO COMERCIAL URUGUAI \\
\hline 15.124 .46 & 4BANCO ECONOMICO & 42.972 .760 & BANCO MINAS & 75.647 .891 & BANCO CALYON BRASIL \\
\hline 15.142 .49 & OBANCO BANEB & 43.073 .394 & BANCO NOSSA CAIXA & 76.492 .172 & BANCO BANESTADO \\
\hline 15.173 .77 & 6BANCO CAPITAL & 46.570 .388 & BANCO NORCHEM & 78.336 .633 & BANCO ARAUCARIA \\
\hline 15.207 .24 & 4BANCO MARKA & 49.336 .860 & ING BANK NV & 78.626 .983 & BANCO VR \\
\hline 17.157 .77 & 7BANCO NACIONAL & 50.585 .090 & BANCO SCHAHIN & 78.632 .767 & BANCO OURINVEST \\
\hline 17.184 .03 & 7BANCO MERCANTIL DO BRASII & 52.940 .319 & BANCO FENICIA & 80.271 .455 & BANCO MAXINVEST \\
\hline 17.298 .09 & 2BANCO BEMGE & 52.940 .350 & BANCO CREFISUL & 83.876 .003 & BANCO BESC \\
\hline 17.346 .22 & 2MILBANCO & 54.403 .563 & BANCO ARBI & 90.400 .888 & BANCO SANTANDER MERIDIONAL \\
\hline 17.348 .15 & 2BANCO DRACMA & 56.077 .217 & BANCO TENDENCIA & 90.731 .688 & BANCO FORD \\
\hline 17.351 .18 & OBANCO TRIANGULO & 57.561 .615 & BANCO FINASA & 91.884 .981 & BANCO JOHN DEERE \\
\hline 21.562 .96 & 2BANCO CREDIREAL & 57.839 .805 & BANCO TRICURY & 92.702 .067 & BANCO EST. RIO GRANDE DO SUL \\
\hline 22.531 .84 & 2BANCO DO PROGRESSO & 57.869 .166 & BANCO MATRIX & 92.874 .270 & BANCO AJRENNER \\
\hline 27.937.33 & 3BANCO BRJ & 57.950 .982 & BANCO LAVRA & 92.894 .922 & BANCO MATONE \\
\hline 28.127 .60 & 3BANCO BANESTES & 58.017 .179 & BANCO VOLVO BRASIL & 93.088 .433 & BANCO AXIAL \\
\hline 28.157 .20 & 4BANCO SANTOS NEVES & 58.160 .789 & BANCO SAFRA & 96.230 .370 & BANCO DAS NACOES \\
\hline
\end{tabular}


Tabela 12 - Bancos Utilizados Relação Risco e $H(H H I)$

\begin{tabular}{|c|c|}
\hline CNPJ & NOME_CNPJ \\
\hline 0 & BANCO DO BRASIL \\
\hline 208 & BRB - BANCO DE BRASILIA \\
\hline 86.413 & BANCO BNL DO BRASIL \\
\hline 360.305 & CAIXA ECONOMICA FEDERAL \\
\hline 1.540 .541 & BANCO BEG \\
\hline 4.902 .979 & BANCO BASA \\
\hline 4.913 .711 & BANCO BANPARA \\
\hline 6.271 .464 & BANCO BEM \\
\hline 6.833 .131 & BANCO BEP \\
\hline 7.196 .934 & BANCO BEC \\
\hline 7.207 .996 & BANCO BMC \\
\hline 7.237 .373 & BANCO DO NORDESTE DO BRASIL \\
\hline 7.450 .604 & BCO INDUSTRIAL E COMERCIAL \\
\hline 10.866 .788 & BANCO BANDEPE \\
\hline 13.009 .717 & BANCO BANESE \\
\hline 17.184 .037 & BANCO MERCANTIL DO BRASIL \\
\hline 17.298 .092 & BANCO BEMGE \\
\hline 17.351 .180 & BANCO TRIANGULO \\
\hline 28.127 .603 & BANCO BANESTES \\
\hline 28.195 .667 & BANCO ABC BRASIL \\
\hline 30.131 .502 & BANCO UBS \\
\hline 30.306 .294 & BANCO PACTUAL \\
\hline 31.516 .198 & BANCO ITAÚ - BBA \\
\hline 33.066 .408 & BANCO ABN AMRO REAL \\
\hline 33.098 .518 & BANCO FININVEST \\
\hline 33.124 .959 & BANCO RURAL \\
\hline 33.479 .023 & BANCO CITIBANK \\
\hline 33.644 .196 & BANCO FATOR \\
\hline 33.700 .394 & UNIBANCO \\
\hline 33.852 .567 & BANCO HSBC \\
\hline 33.870 .163 & BANCO ALVORADA \\
\hline 43.073 .394 & BANCO NOSSA CAIXA \\
\hline 58.160 .789 & BANCO SAFRA \\
\hline 58.257 .619 & BANCO SANTOS \\
\hline 59.109 .165 & BANCO VOLKSWAGEN \\
\hline 59.118 .133 & BANCO LUSO BRASILEIRO \\
\hline 59.285 .411 & BANCO PANAMERICANO \\
\hline 59.438 .325 & AMERICAN EXPRESS BANK \\
\hline 59.588 .111 & BANCO VOTORANTIM \\
\hline 60.394 .079 & BANKBOSTON BANCO MULTIPLO \\
\hline 60.498 .557 & BANCO DE TOKYO-MITSUBISHI \\
\hline 60.701 .190 & BANCO ITAÚ \\
\hline 60.746 .948 & BANCO BRADESCO \\
\hline 60.889 .128 & BANCO SOFISA \\
\hline 60.898 .723 & BANCO BCN \\
\hline 60.942 .638 & BANCO SUDAMERIS BRASIL \\
\hline 61.065 .421 & BANCO MERCANTIL DE SPO \\
\hline 61.186 .680 & BANCO BMG \\
\hline 61.199 .881 & BANCO DIBENS \\
\hline 61.411 .633 & BANCO BANESPA \\
\hline 61.472 .676 & BANCO SANTANDER BRASIL \\
\hline 61.533 .584 & BANCO SOCIETE GENERALE \\
\hline 62.136 .254 & BANCO CRUZEIRO DO SUL \\
\hline 62.232 .889 & BANCO DAYCOVAL \\
\hline 62.331 .228 & DEUTSCHE BANK $S^{\mathrm{a}}$ \\
\hline 69.141 .539 & BANCO CREDIBEL \\
\hline 76.492 .172 & BANCO BANESTADO \\
\hline 83.876 .003 & BANCO BESC \\
\hline 90.400 .888 & BANCO SANTANDER MERIDIONAL \\
\hline 92.702 .067 & BANCO EST. RIO GRANDE DO SUL \\
\hline
\end{tabular}




\section{B. TESTE PARA A ESTATÍSTICA-H=0 (MONOPÓLIO) E ESTATÍSTICA-H=1 (CONCORRÊN- CIA)}

O teste de restrição parte do modelo irrestrita e testa a restrição para monopólio $(H 1+H 2+H 3=$ $0)$ à esquerda e a restrição para concorrência perfeita $(H 1+H 2+H 3=1$ ou $H 1=1-H 2-H 3)$ à direita.

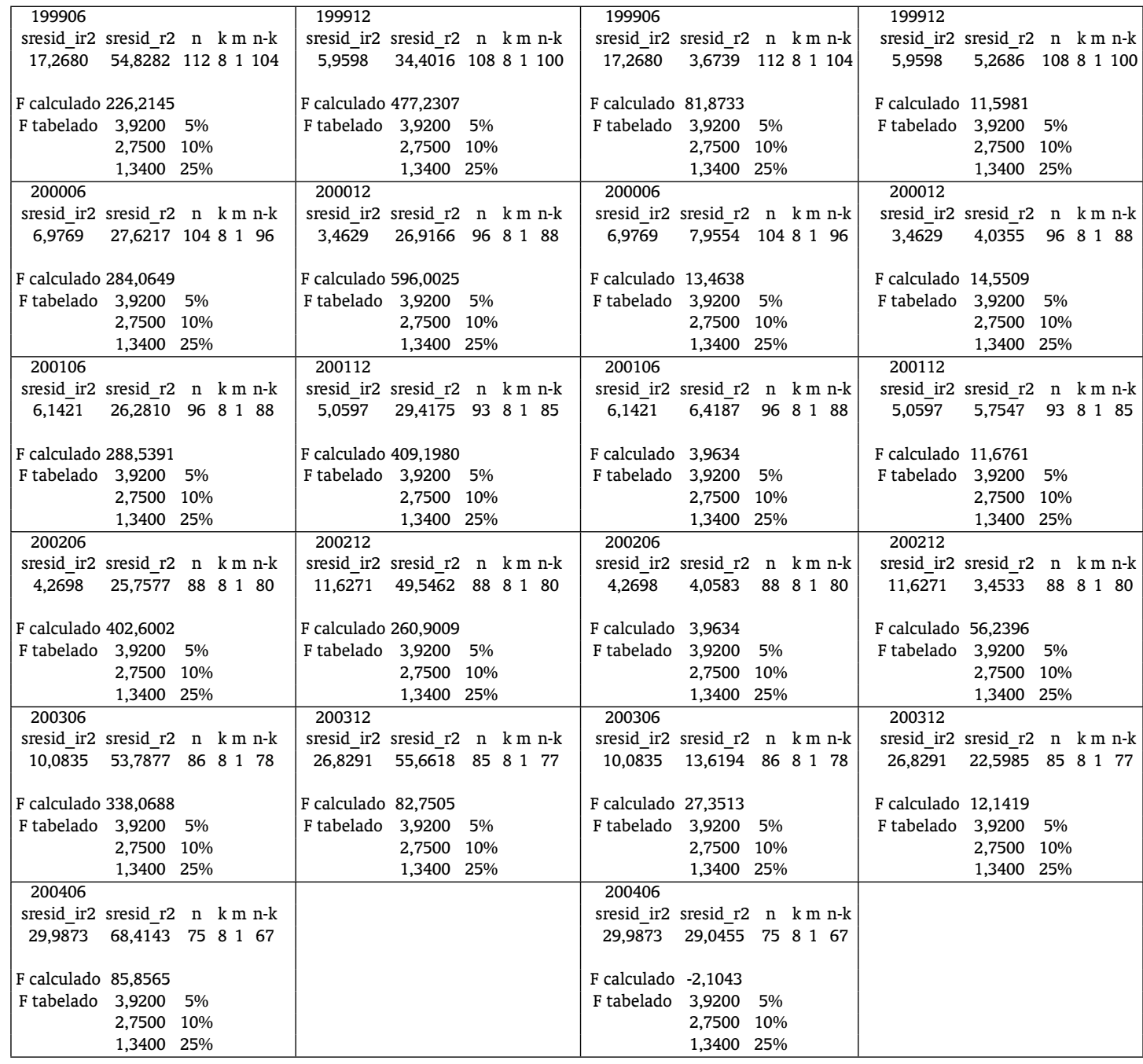

\section{TESTES PARA TERMOS IGUAIS, EFEITOS FIXOS E ALEATÓRIOS}

\section{C.1. Teste para Termos Constantes Iguais}

$H 0$ : termos constantes são iguais, $\alpha_{1}=\alpha_{2}=\cdots=\alpha_{n}$

$H 1$ : termos constantes tem pelo menos um diferente.

$$
F(n-1, n T-n-k)=\frac{\frac{e^{\prime} e_{F E}-e^{\prime} e_{P O O L}}{n-1}}{\frac{e^{\prime} e_{F E}}{n T-n-k}}
$$




\begin{tabular}{ccc}
\hline & Estatística $\mathrm{H}$ & HHI \\
\hline$F_{\text {Calculado(659,6586) }}$ & 7,2774 & 7,6415 \\
\hline$F_{\text {Tabelado(659,6592) }}$ & 1,320 & 1,3200 \\
\hline
\end{tabular}

Como $F_{\text {Calculado }}>F_{\text {Tabelado }}$ a hipótese HO (termos constantes iguais) é rejeitada.

\section{C.2. Teste para Verificar Efeitos Fixos ou Aleatórios de Hausman}

$\begin{cases}H 0: \operatorname{Cov}\left(C_{i}, X_{i t}\right)=0 & \text { Estimadores são consistentes, OLS é ineficiente, Ef. Aleatórios } \\ H 1: \operatorname{Cov}\left(C_{i}, X_{i t}\right) \neq 0 & \text { Estimador GLS é inconsistente, Efeitos Fixos }\end{cases}$

$$
\chi_{\text {calculado }}^{2}=\left(b_{G L S}-b_{O L S}\right)^{\prime} \sum^{-1}\left(b_{G L S}-b_{O L S}\right)
$$

onde sigma é a diferença entre as variâncias, ou seja, $\left(e_{o l s} \times e_{o l s}\right)-\left(e_{g l s} \times e_{g l s}\right)$.

\begin{tabular}{ccc}
\hline & Estatística $\mathrm{H}$ & $\mathrm{HHI}$ \\
\hline Estatística de Hausman & 32,6955 & 118,8348 \\
\hline Qui-quadrado $_{\mathrm{m} \text { graus de liberdade }}$ & 21,955 & 21,9550 \\
\hline
\end{tabular}

onde: $\mathrm{m}=8$, é o número de variáveis explicativas que variam no tempo.

A estatística calculada é maior do que a estatística tabelada. Assim, rejeitamos $H 0$, que é a possibilidade de nosso modelo estar tratando de efeitos aleatórios. Logo, o modelo é de efeitos fixos.

\section{C.3. Teste de Autocorrelação para Efeitos Fixos de Baltagi}

Hipótese de Nula é igual a não ter correlação.

\begin{tabular}{rrc}
\hline & Estatística $\mathrm{H}$ & $\mathrm{HHI}$ \\
\hline Estatística $_{\text {Calculada }}$ & 13,2153 & 13,1900 \\
\hline Normal-padrão & 3,000 & 3,0000 \\
\hline
\end{tabular}

Rejeitamos a hipótese de ausência de autocorrelação.

\section{C.4. Teste de Heterocedasticidade de Bickel}

Na hipótese nula os coeficientes são iguais, não tem heterocedasticidade.

$$
F=\frac{R_{I R}^{2}-R_{R}^{2} / m}{1-R_{I R}^{2} /(n-k)}
$$

são três restrições lineares, $b r t=b r t 2=b r t 3=b r t 4=b r t 5=0$, logo $m=5 .(n-k)=660-5=$ 655 .

\begin{tabular}{rcc}
\hline & Estatística $\mathrm{H}$ & HHI \\
\hline Estatística $_{\text {Calculada }}$ & 96,7857 & 70,0078 \\
\hline Normal-padrão & 1,410 & 1,4100 \\
\hline
\end{tabular}


Logo, existe heterocedasticidade e a variância não é constante.

\begin{tabular}{rcc}
\hline \multicolumn{3}{l}{ Dependent Variable: RESID2? } \\
\hline \multicolumn{3}{l}{ Method: GLS (Cross Section Weights) } \\
Sample: 1999:1 $2004: 1$ \\
\hline Variable & Coefficient & t-Statistic \\
\hline BASILEST? & $-0,0222$ & $-0,5824$ \\
BASILEST2? & 0,0959 & 0,5086 \\
BASILEST3? & $-0,0571$ & $-0,1937$ \\
BASILEST4? & 93,6324 & 3,0830 \\
BASILEST5? & $-233,3089$ & $-3,2428$ \\
Fixed Effects & & \\
R-squared & 0,7787 & \\
Adj. R-squared & 0,7549 & \\
\hline
\end{tabular}

\begin{tabular}{rcc}
\hline \multicolumn{3}{l}{ Dependent Variable: RESID2? } \\
\multicolumn{3}{l}{ Method: GLS (Cross Section Weights) } \\
Sample: 1999:1 $2004: 1$ \\
\hline Variable & Coefficient & t-Statistic \\
\hline BASILEST? & $-0,2168$ & $-2,4483$ \\
BASILEST2? & 0,9975 & 2,3173 \\
BASILEST3? & $-1,3768$ & $-2,1527$ \\
BASILEST4? & 217,7620 & 3,1846 \\
BASILEST5? & $-507,3050$ & $-3,1884$ \\
Fixed Effects & & \\
R-squared & 0,7563 & \\
Adj. R-squared & 0,7301 & \\
\hline
\end{tabular}

\begin{tabular}{|c|c|c|}
\hline \multicolumn{3}{|c|}{ Dependent Variable: RESID2? } \\
\hline \multicolumn{3}{|c|}{ Method: GLS (Cross Section Weights) } \\
\hline \multicolumn{3}{|c|}{ Sample: 1999:1 2004:1 } \\
\hline Variable & Coefficient & t-Statistic \\
\hline RISKEST? & 0,0060 & 2,0645 \\
\hline \multicolumn{3}{|l|}{ Fixed Effects } \\
\hline R-squared & 0,6809 & \\
\hline Adj. R-squared & 0,6490 & \\
\hline
\end{tabular}

\begin{tabular}{|c|c|c|}
\hline \multicolumn{3}{|c|}{ Dependent Variable: RESID2? } \\
\hline \multicolumn{3}{|c|}{ Method: GLS (Cross Section Weights) } \\
\hline \multicolumn{3}{|c|}{ Sample: 1999:1 2004:1 } \\
\hline Variable & Coefficient & t-Statistic \\
\hline RISKEST? & $-0,0017$ & $-0,5525$ \\
\hline \multicolumn{3}{|l|}{ Fixed Effects } \\
\hline R-squared & 0,6784 & \\
\hline Adj. R-squared & 0,6462 & \\
\hline
\end{tabular}

